\title{
BAS VAN FRAASSEN Y LA LEY DE HARDY-WEINBERG: UNA DISCUSIÓN Y DESARROLLO DE SU DIAGNÓSTICO
}

\author{
PABLO LORENZANO \\ Universidad Nacional de Quilmes/CONICET
}

\begin{abstract}
The aim of this article is to discuss and develop the diagnose of the HardyWeinberg law made by van Fraassen (1987, p. 110), according to which: 1) that law cannot be considered a law used as an axiom for the classical population genetics as a whole, since it is an equilibrium-law that holds only under certain special conditions; 2) it just determines a subclass of models; 3) its generalization shades off into logical vacuity; and 4) more complex variants of the law can be deduced for more realistic assumptions. The discussion and development of such a diagnose will be carried out with the notions of another semantic conceptions of theories, related to that of van Fraassen, namely, the structuralist view of theories, and a rational reconstruction of classical population genetics made within the framework of such a metatheory, also presented in this paper.
\end{abstract}

\section{Introducción}

Por un lado, en toda presentación de la genética (clásica) de poblaciones (mendeliana), se suele mencionar a la llamada "ley de Hardy-Weinberg" como a la ley principal o fundamental de dicha teoría. Pero, por el otro, Bas van Fraassen afirma que, si bien

[1]a literatura científica sobre una teoría hace relativamente sencillo identificar y aislar clases de estructuras para ser incluidas en la clase de los modelos teóricos [...] [es], por el contrario, usualmente muy difícil encontrar leyes que pudieran ser utilizadas como axiomas para la teoría como un todo. Aparentes leyes que ocurren frecuentemente son a menudo descripciones de subclases especiales de modelos, su generalización siendo dejada vaga y a menudo cayendo en vacuidad lógica. (van Fraassen 1987, p. 110)

Y cita, como dos ejemplos, a la ecuación de Schrödinger de la mecánica cuántica y a la ley de Hardy-Weinberg de la genética de poblaciones. De ésta, en particular, afirma que

Principia, 12(2) (2008), pp. 121-54. Published by NEL — Epistemology and Logic Research Group, Federal University of Santa Catarina (UFSC), Brazil. 
aparece en toda discusión de fundamentos del tema. Pero difícilmente pudiera ser un axioma de la teoría, ya que sólo vale bajo ciertas condiciones especiales. Si consideramos el caso general, encontramos un hecho lógico: que ciertos supuestos implican que describen un equilibrio que puede ser alcanzado en una generación y mantenido. Los supuestos son muy especiales y muchas variantes complejas de la ley pueden ser deducidas para supuestos más realistas - en una secuencia abierta e indefinida de sofisticaciones. (van Fraassen 1987, p. 110)

El objetivo de este trabajo es discutir y desarrollar este diagnóstico, de acuerdo con el cual la ley de Hardy-Weinberg: 1) no puede ser considerada una ley a ser utilizada como un axioma de la teoría genética de poblaciones, pues es una ley de equilibrio que sólo vale bajos ciertas condiciones especiales, 2) sólo determina una subclase de modelos, 3) su generalización resulta siendo vacua, y 4) variantes complejas de la ley pueden ser deducidas para supuestos más realistas. Para ello, me valdré de ciertas nociones propuestas por otra de las concepciones semánticas afín a la desarrollada por van Fraassen, a saber: la concepción estructuralista de las teorías. En particular, utilizaré las nociones de ley fundamental, ley especial y de la relación de especialización que existe entre ambos tipos de leyes, tratando de mostrar, a partir de una reconstrucción de la genética (clásica) de poblaciones (mendeliana) realizada en el marco de la metateoría estructuralista, que la llamada "ley de Hardy-Weinberg" (a pesar de lo no del todo adecuado históricamente, pues en la forma que se la suele presentar no la encontramos ni en Hardy 1908 ni en Weinberg 1908), efectivamente no debería ser considerada la ley fundamental de dicha teoría, sino una ley especial (en particular, una especialización no-terminal). Esto significa que es susceptible de ser obtenida a partir de lo que podría ser considerada la ley fundamental de la genética de poblaciones (explicitada en este trabajo de reconstrucción y que posee la característica de ser "cuasivacua" o "empíricamente irrestricta"), mediante un proceso (no-deductivo, en realidad) denominado "especialización", que sólo se aplicaría a ciertos sistemas particulares que satisfacen determinadas condiciones o restricciones especiales y que el proceso de especialización nos permitiría obtener otras leyes especiales, que valen en distintas circunstancias "más realistas".

\section{La ley de Hardy-Weinberg}

La habitualmente llamada "ley de Hardy-Weinberg", que, debido a su atribución a Hardy (1908) y a Weinberg (1908), también es denominada "principio (o ecuación o fórmula) de Hardy-Weinberg" y sólo raramente "ley de Hardy-Weinberg-

Principia, 12(2) (2008), pp. 121-54. 
Castle", en alusión al trabajo de Castle (1903), y muy difícilmente "ley de CastlePearson-Hardy-Weinberg", también en referencia a Pearson (1903), fue conocida en el mundo sajón hasta el año 1943 como "ley de Hardy" (ver Stern 1943 y Crow 1999). Esta ley, en su formulación estándar, que no es la que encontramos en los textos mencionados, establece que, si se considera un único gen con sólo dos alelos, A y a, se puede demostrar matemáticamente que, si se cumplen ciertas condiciones, entonces las frecuencias, o proporciones relativas, de los alelos A y $a$ en la población no cambiarán de una generación a otra, luego de la segunda generación. $\mathrm{O}$, lo que es lo mismo, que el reservorio génico estará en un estado estacionario - en un equilibrio - con respecto a estos alelos. Este equilibrio de las frecuencias genotípicas se expresa con la siguiente ecuación o expresión algebraica: $p^{2}+2 p q+q^{2}=1$, en donde $p$ designa la frecuencia de un alelo, $p^{2}$ designa la frecuencia de individuos homocigóticos para un alelo, $q$ designa la frecuencia del otro, $q^{2}$ la frecuencia de individuos homocigóticos para el otro alelo, $2 p q$ es la frecuencia de heterocigotos, y la suma de $p$ y $p$ siempre debe ser igual a 1,0 sea, $p+q$ representa el $100 \%$ de los alelos de ese gen particular en el reservorio génico, pudiéndose obtener $q=1-p .^{1}$

Las condiciones que deben darse para que se cumpla (el equilibrio planteado por) la ley son las siguientes: 1) que los organismos de la población sean diploides; 2) que la reproducción sea sexual; 3) que las generaciones no se superpongan, e.e. que los individuos pertenezcan a distintas generaciones no se crucen o apareen; 4) que el cruzamiento o apareamiento entre individuos sea al azar, o sea, azaroso o aleatorio; 5) que el tamaño de la población sea muy grande (al menos lo suficientemente grande como para que se apliquen las leyes de la probabilidad);6) que la migración sea negligible; 7) que la mutación pueda ser ignorada; y 8) que la selección natural no afecte a los alelos en cuestión.

Por otro lado, se suelen mencionar, además del cruzamiento o apareamiento no aleatorio o preferencial, los cuatro siguientes factores evolutivos o fuerzas evolutivas, que serían las "causas" de los cambios en las poblaciones: 1) la deriva génica (e.e. el azar, por sí mismo, pueda alterar la frecuencia de los alelos); 2) la migración (e.e el desplazamiento neto de individuos con sus genes hacia el interior de la población —inmigración — o hacia afuera —emigración-); 3) la mutación; y 4) la selección natural (entendida como tasa de reproducción diferencial de los diferentes genotipos presentes en la población; e.e. hay diferencia en el éxito reproductivo de los genotipos considerados, es decir, llevar diferentes combinaciones alélicas confiere ventaja a sus portadores; así, la progenie de todos los apareamientos posibles no tiene la misma probabilidad de sobrevivir y reproducirse en la generación siguiente).

Principia, 12(2) (2008), pp. 121-54. 


\section{Las nociones de ley fundamental, de ley especial y de especia- lización en la concepción estructuralista de las teorías}

"Cuando los filósofos discuten leyes de la naturaleza hablan en términos de universalidad y necesidad”, escribe Bas van Fraassen (1989, p. 1). Con estos criterios, sin embargo, parece que no sólo deberían ser descartadas como tales las leyes biológicas, sino también las más respetables leyes físicas. De hecho, debido a la falta de criterios no problemáticos para las leyes de la naturaleza, van Fraassen (1989) propone lisa y llanamente que dispensemos de esa categoría. Su crítica al concepto de necesidad natural o nómica (van Fraassen 1977, 1989, 1993) y su consecuente escepticismo respecto de la noción de ley de la naturaleza es compartido por otros autores, tales como Swartz (1995). Aceptar esto, sin embargo, no implica para ellos que no haya ecuaciones fundamentales o principios básicos de teorías que de hecho estructuren la práctica científica real; excepto que éstas, en oposición a las leyes de la naturaleza, ${ }^{2}$ son concebidas como leyes científicas (Swartz 1995) o leyes de los modelos (van Fraassen 1989, 1993). Tales leyes no son concebidas como regularidades empíricas que gobiernan el mundo natural que nos rodea, independientemente de si los seres inteligentes poseen o no conocimiento de esas regularidades o de si ha sido desarrollada una representación simbólica apropiada o no para al menos algunas de esas regularidades, sino como creaciones humanas, e.e., como regularidades del mundo natural (o, mejor aún, del mundo modelado) conocidas por nosotros y que han sido puestas en formas simbólicas apropiadas y han sido adoptadas en nuestro esfuerzo colectivo por explicar, predecir y controlar dicho mundo. En lo que sigue, cuando hablemos de leyes, lo haremos para referirnos a las leyes científicas o de la ciencia.

Por otro lado, sin embargo, a pesar de los sucesivos y renovados esfuerzos realizados, todavía no disponemos de un concepto satisfactorio de ley científica, e.e. de un conjunto adecuado de condiciones necesarias y suficientes precisas como criterio para que un enunciado sea considerado una "ley". ${ }^{3}$ Más aún, "[e]s probable que ningún conjunto tal de condiciones pueda ser alguna vez encontrado que apareciera como satisfactorio para todos, ya que la noción de ley es una noción fuertemente histórica, dependiente de la disciplina" (Balzer, Moulines \& Sneed 1987, p. 19). Dentro de la tradición estructuralista, cuando de manera por lo general dispersa, pero recurrente, se trata el tema de las leyes, las discusiones, aun desde sus comienzos con Sneed (1971), si bien no con esa terminología, se centran en aquellas que, a partir de Stegmüller (1973), son denominadas "leyes fundamentales" de una teoría. ${ }^{4}$ Y cuando se discuten los criterios para que un enunciado sea considerado como una ley fundamental de una teoría, se tiende

Principia, 12(2) (2008), pp. 121-54. 
a hablar más bien de "condiciones necesarias" (Stegmüller 1986), de "condiciones necesarias débiles" (Balzer, Moulines \& Sneed 1987) o, mejor aún, sólo de “'síntomas', algunos incluso formalizables" (Moulines 1991), aunque "en cada caso particular de reconstrucción de una teoría dada, parece, por regla general, ser relativamente fácil concordar, en base a consideraciones informales o semiformales (por ejemplo, sobre su papel sistematizador o su carácter cuasi-vacuo), en que un determinado enunciado debe tomarse como ley fundamental de la teoría en cuestión" (Moulines 1991, p. 233).

En Stegmüller (1986), se mencionan dos criterios como condiciones necesarias para ser ley fundamental: 1) el carácter arracimado o sinóptico; y 2) que valga en todas las aplicaciones intencionales. El primero de los criterios, su carácter sinóptico, que ya había hecho aparición en la literatura estructuralista en Stegmüller (1979a, 1979b) y que es igualmente recogido en Balzer, Moulines \& Sneed (1987) y en Moulines (1991), ha recibido distintas formulaciones, algunas más fuertes que otras. De acuerdo con la más fuerte de ellas, "cualquier formulación correcta de la ley debería incluir necesariamente todos los términos relacionales (e implícitamente también todos los conjuntos básicos) y, por tanto, en definitiva, todos los conceptos fundamentales que caracterizan dicha teoría" (Moulines 1991, p. 234). Planteado de este modo, sin embargo, este rasgo, como reconoce el propio Moulines (1991, p. 233-4), no es poseído por todos los probables candidatos a leyes fundamentales - por ejemplo, por las leyes fundamentales de la mecánica relativista del continuo y de la electrodinámica, que, de acuerdo con la reconstrucción ofrecida por Bartelborth (1988) y la discusión que éste efectúa de dicho rasgo (1988, p. 19ss, 45s, 53), "no parecen poder reformularse como leyes sinópticas de manera plausible y natural" (Moulines 1991, p. 234)_, aunque sí por una gran clase de leyes fundamentales detectadas hasta ahora, convirtiéndose así en un "[s]íntoma frecuente" (p. 235).

En las formulaciones de este criterio más débiles que la proporcionada por Moulines, no se exige que en las leyes fundamentales ocurran todos los conceptos fundamentales, sino sólo "varias de las magnitudes" (Stegmüller 1986, p. 23), "diversas funciones" (Stegmüller 1986, p. 93), "posiblemente muchos conceptos teóricos y no-teóricos" (Stegmüller 1986, p. 386), "casi todos" (Balzer, Moulines \& Sneed 1987, p. 19) o "al menos dos" (Stegmüller 1986, p. 151). De este modo, pueden ser consideradas leyes fundamentales proposiciones que quedaban excluidas mediante la formulación más fuerte del criterio y que probablemente hubiera que tomar como tales, diferenciándose por otro lado de las "meras" caracterizaciones mencionadas en la nota anterior (o inclusive de posibles leyes especiales), en las que ocurren los términos de manera aislada. ${ }^{5}$

Principia, 12(2) (2008), pp. 121-54. 
El segundo de los criterios para que un enunciado sea considerado como una ley fundamental recogido en Stegmüller (1986) de manera explícita, pero que de algún modo u otro se encuentra presente en toda la literatura estructuralista, "es la validez en todas las aplicaciones intencionales" (p. 93). De acuerdo con este criterio, no es necesario que las leyes fundamentales de las teorías posean un alcance ilimitado, se apliquen en todo tiempo y lugar y tengan como universo de discurso algo así como una "gran aplicación", que constituye un modelo único o "cósmico" (Stegmüller 1979b, Mosterín 1984). De hecho, sólo las leyes fundamentales de algunas teorías cosmológicas, que son aplicables al modelo cósmico, y las leyes de la "gran teoría unificada" ("Great Unified Theory" o GUT), en caso de existir, son universales en ese sentido. Sin embargo, esta no es la situación habitual. Las leyes de la física, y lo mismo ocurre con las leyes de las otras ciencias como las biológicas, normalmente se aplican a sistemas empíricos parciales y bien delimitados (el conjunto de aplicaciones intencionales), y no al modelo cósmico. Por otro lado, este criterio permitiría discriminar las leyes fundamentales de las leyes especiales, que, aunque sinópticas, sólo son válidas en algunas, pero no en todas, las aplicaciones de la teoría.

En Moulines (1991), junto al ya aludido carácter sinóptico, se mencionan, como vimos más arriba, aunque sin desarrollar, otros dos "síntomas" de las leyes fundamentales, que también suelen figurar en distintos escritos estructuralistas: su papel sistematizador y su carácter cuasi-vacuo. El carácter cuasi-vacuo (empíricamente) de las leyes fundamentales se refiere al hecho de que éstas son altamente abstractas, esquemáticas, lo suficientemente vacías y con ocurrencia esencial de términos $\mathrm{T}$-teóricos como para resistir cualquier posible refutación, pero que, sin embargo, adquieren contenido empírico específico (y la posibilidad de ser contrastadas) a través de un proceso no-deductivo conocido con el nombre de "especialización". Dicho proceso, por medio del cual se obtienen las leyes más específicas, llamadas "especiales", ${ }^{6}$ a partir de una(s pocas) ley(es) fundamental(es) de una teoría, consiste en la introducción de ulteriores restricciones, constricciones o especificaciones a (algunos de los componentes de) dicha(s) ley(es), de forma tal de irse concretando progresivamente en direcciones diversas, hasta desembocar finalmente en las llamadas "especializaciones terminales", en donde todos sus componentes se encuentran especificados. ${ }^{7}$ Este carácter cuasi-vacuo de las leyes fundamentales ha seguramente contribuido a que algunos autores hayan dudado de su naturaleza empírica y hayan propuesto considerarlas como "no-empíricas", "analíticas", "a priori”, "estipulaciones tautológicas”, "meras convenciones" o "meras definiciones" de al menos alguno de los términos T-teóricos que allí figuran. Moulines propone la denominación de "empíricamente irrestric-

Principia, 12(2) (2008), pp. 121-54. 
tos" (1982, p. 96) para este tipo de enunciados que, por un lado, son irrefutables o empíricamente vacuos, pero que, por otro lado, lo son en un sentido distinto a los ejemplos paradigmáticos de enunciados analíticos, tales como "Todos los solteros son no casados". Estos enunciados son irrefutables o empíricamente vacuos, ya que su estructura es tal que cualquier sistema empírico - formulado en el vocabulario no-teórico (anterior, previamente disponible o independiente) de la teoría - puede ser "extendido" o "completado" trivialmente — mediante la adición de los términos T-teóricos- hasta transformarse en un modelo completo (teórico) de la teoría en cuestión, satisfaciendo por tanto su(s) ley(es) fundamental(es). Son, además, distintos de los enunciados tradicionalmente considerados analíticos, pues si bien hay una relación estrecha entre los términos T-teóricos y las leyes fundamentales mediante los cuales son introducidos - a saber: que su extensión sólo puede ser determinada presuponiendo lógicamente la validez de dichas leyes-, éstas no "definen" en sentido estricto a los términos T-teóricos, ya que violan los criterios de eliminabilidad y no-creatividad que deben ser satisfechos por las definiciones ("explícitas" o "lógicas"). ${ }^{8}$

El otro de los "síntomas" mencionados por Moulines, el papel sistematizador de las leyes fundamentales, podría entenderse como estableciendo que éstas posibilitan incluir dentro de una misma teoría diversas aplicaciones a distintos sistemas empíricos, al proveer una guía y un marco conceptual para la formulación de otras leyes (las denominadas "especiales") que, como vimos más arriba, introducen restricciones adicionales respecto de las leyes fundamentales y se aplican así a los sistemas empíricos en particular. Merced entonces al proceso de "especialización", que estructura a las teorías de un modo fuertemente jerárquico, y a la obtención de aplicaciones "exitosas", se consiguen integrar los distintos sistemas empíricos bajo una misma conceptualización, en donde la(s) ley(es) fundamental(es) ocupan un lugar central.

\section{El concepto estructuralista de teoría}

Antes de presentar nuestro análisis de la genética clásica de poblaciones, introduciremos las herramientas conceptuales con las que se realizará dicho análisis. Para la concepción estructuralista de las teorías científicas - como para toda concepción semántica o modelo-teórica - una teoría empírica no es una entidad lingüística, sino que considera que el componente más básico para la identidad de una teoría es una clase de modelos en el sentido de Tarski. Sin embargo, y a diferencia de otra de las concepciones de la familia semanticista, la concepción suppesiana de las teorías, para la concepción estructuralista una teoría no debe ser identifica-

Principia, 12(2) (2008), pp. 121-54. 
da con una clase de estructuras (o modelos), sino, antes bien, con una serie de clases de estructuras jerárquicamente organizadas; cada clase de estructuras es denominada "elemento teórico" y a la serie total la llamamos "red teórica"; una teoría es (usualmente) una red jerárquica de elementos teóricos. El tipo más simple de estructura conjuntista susceptible de ser considerada una elucidación formal del concepto intuitivo de teoría científica es, entonces, el denominado elemento teórico $\mathbf{T}$ y puede ser identificado, en una primera aproximación, con el par ordenado consistente en un núcleo teórico $\mathrm{K}$ y en un conjunto de aplicaciones pretendidas, propuestas o intencionales $\mathrm{I}: \mathrm{T}=\langle\mathrm{K}, \mathrm{I}\rangle$. El núcleo $\mathrm{K}$-la parte formal de la teoría, que expresa los recursos conceptuales a diferentes niveles y las restricciones-leyes que según la teoría rigen su ámbito de estudio- es, a su vez, un conjunto ordenado formado por los siguientes elementos: la clase de modelos potenciales $\mathbf{M}_{\mathrm{p}}$, la clase de modelos $\mathbf{M}$, la clase de modelos parciales $\mathbf{M}_{\mathrm{pp}}$, la clase de condiciones de ligadura $\mathbf{C}$ y la clase de vínculos interteóricos L. Los modelos potenciales $\mathbf{M}_{\mathbf{p}}$ simbolizan la clase total de entidades que satisfacen las condiciones que caracterizan matemáticamente al aparato conceptual de la teoría y son aquellas estructuras de las cuales tiene sentido preguntarse si son modelos, pero que todavía no se sabe si efectivamente lo son. Los modelos actuales $\mathbf{M}$ simbolizan las entidades que satisfacen la totalidad de las condiciones introducidas, es decir, que además satisfacen la(s) ley(es) fundamental(es) de la teoría, siendo así la contraparte modelo-teórica de tal(es) ley(es). Los denominados modelos (potenciales) parciales $\mathbf{M}_{\mathrm{pp}}$ que describen, mediante conceptos no-teóricos relativos a la teoría en cuestión, los sistemas posibles a los que es concebible aplicar dicha teoría, constituyen la "base empírica" de la teoría. El estructuralismo rechaza la distinción "teórico/observacional" por ambigua. Esta distinción esconde en realidad dos distinciones no coextensivas: "observacional/no observacional", de un lado, y "no teórico/teórico", de otro. Para el análisis de la estructura local de las teorías, la distinción relevante es la segunda. Ahora bien, esta distinción no es una distinción absoluta, sino que está relativizada a las teorías. Un término, o un concepto, o una entidad, no es teórico o no teórico sin más, sino relativamente a una teoría dada. Por eso no se debe hablar tanto de teoricidad cuanto de T-teoricidad, teoricidad relativamente a la teoría T. Además, en la tradición estructuralista han sido planteados dos criterios de $\mathrm{T}$-teoricidad: el que llamaremos criterio de $\mathrm{T}$-teoricidad ${ }_{1}$, que es el usual, y el otro, el criterio de $\mathrm{T}$-teoricidad ${ }_{2}$, que encontramos en algunos de los trabajos de Balzer (1985a, 1985b, 1986, 1996) y Gähde $(1982,1983,1984,1990)$. De acuerdo con el criterio de T-teoricidad ${ }_{1}$, un término es T-teórico si todos los métodos de determinación (de la extensión del concepto expresado por el término) presuponen directa o indirectamente la

Principia, 12(2) (2008), pp. 121-54. 
validez de las leyes de $\mathbf{T}$; si alguno no la presupone, e.e. si se puede determinar independientemente de T, el término es T-no-teórico. Mientras que, de acuerdo con el criterio de $\mathbf{T}$-teoricidad 2 , un término es $\mathbf{T}$-teórico si algún método de determinación presupone directa o indirectamente la validez de las leyes de $\mathrm{T}$; si todos no la presuponen, e.e. si sólo puede determinarse mediante otras teorías que no presupongan $\mathbf{T}$, el término es $\mathbf{T}$-no-teórico. Ambos criterios pueden coincidir contingentemente, pero son diferentes. En relación con los términos teóricos, el primero de los criterios es más fuerte que el segundo, ya que lo implica, pero no es implicado por él. La situación inversa es lo que sucede con relación a los términos no-teóricos, en que el segundo de los criterios es más fuerte que el primero, implicándolo, pero no siendo implicado por él. Así, un término puede ser T-teórico y T-no-teórico ${ }_{1}$, como ocurre con la masa en la mecánica clásica del choque, luego del surgimiento de la mecánica clásica de partículas. La T-teoricidad 2 se mantiene en una perspectiva local, pues no considera las posibles relaciones de una teoría con otras; ello hace que sea, en algún sentido, "ahistórica", pues se es T-teórico 2 o no de una vez por todas; y se puede precisar en términos estrictamente formales, de ahí que se suela denominar "criterio formal" de teoricidad. Por el contrario, la $\mathbf{T}$-teoricidad ${ }_{1}$ se sitúa en una perspectiva global, que tiene en cuenta las relaciones interteóricas, e.e. las relaciones que guarda la teoría en cuestión con otras teorías; a diferencia de la concepción anterior es "histórica", pues puede variar con la evolución de la ciencia, como justamente lo demuestra el caso mencionado de la masa en la mecánica clásica del choque, que era Tteórico ${ }_{1}$, hasta el surgimiento de la mecánica clásica de partículas. Por ello, como proponen Díez \& Ibarra (1988), sería mejor llamarles quizás criterios "global” y "local", o "fuerte" y "débil", en vez de "informal" y "formal". Por otro lado, la idea intuitiva básica estructuralista sobre la teoricidad, según la cual un término es T-teórico si es un término propio de la teoría T, introducido por ella, y es $\mathbf{T}$-noteórico si es un concepto previamente disponible a $\mathbf{T}$, se recoge en el criterio de T-teoricidad 1 y no (siempre), está claro, en el criterio de $\mathbf{T}$-teoricidad 2 . Esta idea nos dice que un término sólo puede ser propiamente teórico en una teoría y ello sólo es cierto en la $\mathbf{T}$-teoricidad ${ }_{1}$. Además, es en base a la $\mathbf{T}$-teoricidad ${ }_{1}$ como se suele establecer la distinción crucial entre $\mathbf{M}_{\mathrm{p}}$ y $\mathbf{M}_{\mathrm{pp}}$. El conjunto de los $\mathbf{M}_{\mathrm{pp}}$ es el conjunto de los modelos potenciales $\mathbf{M}_{\mathrm{p}}$ una vez que se han recortado de éstos los términos T-teóricos. Los últimos componentes del núcleo son las condiciones de ligadura $\mathbf{C}$ y los vínculos $\mathbf{L}$, que reflejan los relaciones entre los distintos modelos de la misma teoría (o sea, relaciones intermodélicas intrateóricas) o con modelos de otras teorías (es decir, relaciones intermodélicas interteóricas), respectivamente.

Principia, 12(2) (2008), pp. 121-54. 
El conjunto de aplicaciones intencionales I constituye la parte aplicativa del elemento teórico, y especifica, en términos no-teóricos respecto de la teoría, los sistemas empíricos a los que la teoría pretende aplicarse, de los que pretenden que son regidos por sus restricciones-leyes. Ellas, que no pueden ser caracterizadas por medios puramente formales, se individualizan y describen mediante el vocabulario previo a $\mathbf{T}$, esto es, mediante el aparato conceptual T-no-teórico. Por tanto, las aplicaciones pretendidas que conforman la base empírica de la teoría, los "datos" de la teoría, ciertamente están cargados de teoría, pero no de la teoría para la que son datos, sino de otra previa o antecedente. Cada aplicación pretendida es entonces un determinado modelo parcial, por tanto, $\mathbf{I} \subseteq \mathbf{M}_{\mathrm{pp}}$. La selección de las aplicaciones, la determinación de I, contiene elementos pragmáticos ineliminables, pues tal determinación es esencialmente intencional y paradigmática. La determinación es intencional, porque lo que hace de un sistema específico que sea una aplicación pretendida es que sea un objeto intencional de los usuarios de la teoría, e.e. que la comunidad científica tenga la intención de aplicar las constricciones-leyes a tal sistema. Y es paradigmática debido a que el conjunto I no se caracteriza mediante una lista de todos los sistemas empíricos que son aplicaciones intencionales, sino paradigmáticamente, a través de sus semejanzas con las aplicaciones-tipo o típicas, y no por compartir un conjunto de condiciones necesarias y suficientes. La pretensión de que los sistemas empíricos a los que la teoría pretende aplicarse son regidos por sus restricciones-leyes se hace explícita mediante un acto lingüístico o proposicional, mediante una afirmación, la afirmación o aserción "empírica" de la teoría. La aserción empírica afirma que entre los sistemas empíricos de los que queremos dar cuenta y los modelos determinados por las leyes se da cierta relación (de "subsunción": los sistemas empíricos son "subsumidos" bajo modelos que, además, satisfacen las condiciones de ligadura y los vínculos o, como lo plantea van Fraassen 1980, p. 64, los sistemas empíricos son isomórficos con "subestructuras empíricas" de los modelos), con la pretensión de que nuestra teoría representa adecuadamente la "realidad", esto es, que nuestros modelos se "aplican bien" a los sistemas a explicar. Algunos ejemplos de teorías científicas reales pueden ser de hecho reconstruidos mediante un elemento teórico. Sin embargo, esto es verdadero sólo para los tipos más simples de teorías con los que uno se pueda encontrar. A menudo, teorías individuales en el sentido intuitivo deben ser consideradas como agregados de varios (a veces de un gran número de) elementos teóricos. Estos agregados son llamados redes teóricas. Esto refleja el hecho de que muchas teorías poseen leyes de distintos grados de generalidad dentro del mismo marco conceptual. Una teoría no es un tipo de entidad democrática, sino, más bien, un sistema fuertemente jerárquico. La idea

Principia, 12(2) (2008), pp. 121-54. 
es que el conjunto de elementos teóricos represente la estructura (sincrónica) de una teoría en sus diferentes estratos, esto es, en sus diversos niveles de "especificidad". Tal conjunto, partiendo de elementos muy generales, se va concretando progresivamente en diversas direcciones cada vez más restrictivas y específicas, las "ramas" de la red teórica. La relación que se debe dar entre los elementos teóricos para considerar el conjunto una red es de "concreción" o "especificación" o, como se dice en terminología estructuralista, de especialización, que es, como dijimos, una relación no-deductiva, reflexiva, anti-simétrica y transitiva. Una red teórica es un conjunto de elementos teóricos conectados mediante la relación de especialización (concreción, especificación). Un elemento teórico que no es especialización de ningún otro y que contiene la(s) ley(es) fundamental(es), como el aquí presentado, es denominado elemento teórico básico. Aunque puede haber en principio redes teóricas de muchas formas, en todos los casos reconstruidos hasta ahora la red ha resultado ser arbórea, con un único elemento teórico básico en la cúspide, a partir del cual se especializan los restantes en diferentes direcciones, hasta llegar a las especializaciones terminales.

\section{La estructura de la genética clásica de poblaciones ${ }^{9}$}

\subsection{El elemento teórico básico de la genética clásica de poblaciones}

Aquí se introducen los distintos componentes del núcleo teórico de la genética clase de poblaciones - empezando por aquel que determina la clase de los modelos potenciales, para pasar luego a los que identifican la clase de los modelos, la clase de los modelos parciales y la de las condiciones de ligadura- y se caracteriza su campo de aplicaciones propuestas y su aserción empírica. ${ }^{10}$

\subsubsection{El núcleo teórico de la genética clásica de poblaciones}

\subsubsection{Los modelos potenciales de la genética clásica de poblaciones}

El conjunto de los modelos potenciales $\mathbf{M}_{\mathbf{p}}$ está constituido por estructuras que satisfacen ciertas condiciones estructurales (los axiomas impropios) para ciertos conceptos (los conceptos de la teoría), y de las que tiene sentido preguntarse si son modelos actuales de la teoría.

Definición 1. $\mathbf{M}_{\mathrm{p}}(\mathrm{GCP}): x=\left\langle\mathrm{I},\left(\mathrm{C}_{i}\right)_{i \leq k},\left(\mathrm{~F}_{i}\right)_{i \leq s}, \mathrm{FEV}, \mathrm{T},<, \mathrm{APP}, \mathrm{MAT}, \mathrm{DIST}\right.$, DET, COMB $\rangle$ es una genética clásica de poblaciones potencial $\left(x \in \mathbf{M}_{\mathrm{p}}(\mathrm{GCP})\right)$ si y sólo si 
(1) I es un conjunto finito, no-vacío ("individuos": variable $i$ )

(2) $\left(\mathrm{C}_{i}\right)_{i \leq k}$ es un conjunto finito, no-vacío ("tipos de características": variable $c_{i}$ )

(3) $\left(F_{i}\right)_{i \leq s}$ es un conjunto finito, no-vacío ("tipos de factores": variable $f_{i}$ )

(4) FEV es un conjunto finito, no-vacío $(F E V=\{m, n, s, F\})$

(5) $\langle T,<\rangle$ es un orden finito, lineal ("tiempo": variable $t$ )

(6) APP: $\operatorname{Pot}(I) \rightarrow P^{n}$ (“appearance": $\operatorname{APP}($ pop $\left.)=\left\langle\pi_{1}, \ldots, \pi_{n}\right\rangle\right)$

(7) $M A T: \operatorname{Pot}(I) \times \operatorname{Pot}(I) \rightarrow \operatorname{Pot}\left(I^{n}\right)$ es una función parcial ("mator": $\operatorname{MAT}\left(\right.$ pop, $\left.\operatorname{pop}^{\prime}\right)=\left\langle\right.$ pop $\left.\left._{1}, \ldots, \operatorname{pop}_{n}\right\rangle\right)$

(8) DIST: $T \times D(P) \rightarrow D(P)$ es una función parcial ("distributor": $\left.\operatorname{DIST}\left(t,\left\langle r_{1} \pi_{1_{1}}, \ldots, r_{1} \pi_{1_{k}}\right\rangle,\left\langle r_{2} \pi_{2_{1}}, \ldots, r_{2} \pi_{2_{k}}\right\rangle\right)=\left\langle r_{1} \pi_{1_{1}}, \ldots, r_{j} \pi_{i_{j}}, \ldots, r_{k} \pi_{n_{k}}\right\rangle\right)$

(9) DET: $G \rightarrow P$ es suprayectiva ("determiner": $\operatorname{DET}\left(\gamma_{i}\right)=\pi_{j}$ o $\left.\operatorname{DET}\left(\left\langle\gamma_{1}, \ldots, \gamma_{s}\right\rangle\right)=\left\langle\pi_{1}, \ldots, \pi_{k}\right\rangle\right)$

(10) COMB: $\mathrm{T} \times \mathrm{D}(\mathrm{G}) \times \mathrm{FEV} \rightarrow \mathrm{D}(\mathrm{G})$ ("combinator": $\operatorname{COMB}\left(t,\left\langle\alpha_{1} \gamma_{1_{1}}, \ldots, \alpha_{s} \gamma_{1_{s}}\right\rangle,\left\langle\alpha_{1} \gamma_{2_{1}}, \ldots, \alpha_{s} \gamma_{2_{s}}\right\rangle\right.$, fev $)=$ $\left.\left\langle\alpha_{1} \gamma_{1_{1}}, \ldots, \alpha_{j} \gamma_{i_{j}}, \ldots, \alpha_{s} \gamma_{n_{s}}\right\rangle\right)$

\section{Axiomas de interpretación:}

Los objetos que ocurren en el predicado se interpretan del siguiente modo:

(1) I representa un conjunto de individuos. Su característica distintiva es que se cruzan y, de este modo, producen descendencia. $i$ se utiliza como variable de este conjunto. Se escribe, entonces, $i \in I$ para expresar que un individuo cualquiera $i$ está en el modelo. En su interior se distingue entre los individuos progenitores y sus descendientes. Si bien los verdaderos portadores de fenotipos y de genotipos son individuos, está claro que la genética de poblaciones trata de, justamente, poblaciones. A partir del conjunto de individuos, podemos, sin embargo, definir fácilmente un conjunto de poblaciones POP mediante el conjunto potencia de individuos Pot (I), tal que cada población pop es un subconjunto del conjunto potencia de individuos (cualquier conjunto de individuos, dejando los criterios de identidad para un tratamiento ad hoc en cada caso, p.e. si todos poseen el mismo fenotipo o genotipo o si pertenecen a la misma especie, viven en la misma área o región geográfica, se cruzan entre sí y producen descendencia fértil —estos últimos rasgos son los que caracterizan a las llamadas "poblaciones locales" o "mendelianas", también denominadas "demes" o "subpoblaciones": pop $\subseteq$ Pot $(I)$; el conjunto de poblaciones POP está formado por los individuos miembros de los conjuntos pop, tales que pop $\in$ POP. Así, tenemos la Definición auxiliar 1:

Principia, 12(2) (2008), pp. 121-54. 
conjunto de poblaciones POP: pop $\in$ POP \& pop $\subseteq$ Pot $(I)$. Las diferencias entre las distintas poblaciones progenitoras y las distintas poblaciones de descendientes no son más expresadas como distinciones entre poblaciones, sino como distinciones de fenotipos dentro de la "misma" población. Así, al separar una población comprehensiva pop en dos: $\mathbf{p o p}=\operatorname{pop}_{1} \cup$ pop $_{2}$, donde los individuos en pop $p_{1}$ tienen el fenotipo $\pi_{1}$ y los de pop $_{2}$ tienen el fenotipo $\pi_{2}$, obtenemos la distinción entre poblaciones progenitoras. De manera similar, separando pop en diversas poblaciones: pop $=$ pop $_{1} \cup \ldots \cup$ pop $_{n}$ podemos representar la distinción previa entre diferentes poblaciones en la descendencia. Si pop es un conjunto de individuos y $\pi$ un fenotipo, entonces el conjunto de aquellos miembros de pop que tengan como su fenotipo, $\operatorname{pop}_{\pi}$, es definido como $\operatorname{pop}_{\pi}=\{i \in \operatorname{pop} / \mathrm{APP}(i)=\pi\}$. Permitiendo que $\pi$ varíe a través de todos los fenotipos presentes, los subconjuntos pop $_{\pi}$ agotan la población original pop. En lugar de referir a los conjuntos pop pes $_{\pi}$ usualmente suficiente hablar acerca de sus números de elementos. La cardinalidad de $\operatorname{pop}_{\pi}$ es exactamente la frecuencia relativa de fenotipos $\pi$ 's que ocurren en la población pop. Así el modo en que una población pop dada se separa en diferentes subgrupos está representado unívocamente por la distribución genética correspondiente de frecuencias relativas.

(2) $\left(C_{i}\right)_{i \leq k}$ es un conjunto de "tipos de características". Cada conjunto $C_{i}$ debería ser considerado como una característica y los elementos $c_{i} \in \mathrm{C}_{i}$ como rasgos o expresiones de esa característica, en donde $i \leq k$. Sobre la base de los tipos de características, puede definirse el conjunto $P$ de fenotipos. Teniendo así la Definición auxiliar 2: conjunto de fenotipos $P=\left\{\pi_{1}, \ldots, \pi_{k}\right\}$ : cada fenotipo $\pi \in P$ tiene la forma $\left\langle c_{1}, \ldots, c_{k}\right\rangle$, en donde $c_{1} \in \mathrm{C}_{1}, \ldots, c_{k} \in \mathrm{C}_{k}$. Los individuos, y las poblaciones, se distinguen por su apariencia. Debido a que las aplicaciones propuestas de la genética clásica de poblaciones se limitan normalmente a unas pocas características, no se exige que se caracterice la apariencia total de una población: basta, entonces, interpretar un fenotipo como una o dos expresiones o rasgos de las características que son efectivamente consideradas en una aplicación dada. $\pi$ se utiliza como variable de este conjunto. Se escribe, entonces, $\pi \in P$ para expresar que un fenotipo cualquiera $\pi$ ocurre en el modelo, siendo así $P=\left\{\pi_{1}, \ldots, \pi_{k}\right\}$. Igual que en el caso de los individuos y las poblaciones, se tienen también aquí $k$ fenotipos paternos, simbolizados por $\left\langle\pi_{1_{1}}, \ldots, \pi_{1_{k}}\right\rangle$ y $\left\langle\pi_{2_{1}}, \ldots, \pi_{2_{k}}\right\rangle$, y $k$ fenotipos asociados con los distintos descendientes $n:\left\langle r_{1} \pi_{1_{1}}, \ldots, r_{j} \pi_{i_{j}}, \ldots, r_{k} \pi_{n_{k}}\right\rangle$.

(3) $F_{1}, \ldots, F_{s}$ son conjuntos de "tipos de factores". Para toda $i \leq s$ y cualesquie- 
ra dos factores $f_{1}$ y $f_{2}$, que $f_{1}$ y $f_{2}$ pertenezcan al mismo conjunto $F_{i}$ significa que $f_{1}$ y $f_{2}$ son alelos. Intuitivamente, factores alelos o genes son aquellos que "actúan conjuntamente" en determinar, total o parcialmente, un rasgo particular. Sobre la base de ellos, puede definirse el conjunto de genotipos G. Tenemos así la Definición auxiliar 3: conjunto de genotipos $G=\left\{\gamma_{1}, \ldots, \gamma_{s}\right\}$ : cada genotipo $\gamma \in \mathrm{G}$ tiene la forma de una lista finita de pares de factores alelos $\left\langle\left\langle f_{i_{1}}, f_{i_{2}}\right\rangle, \ldots,\left\langle f_{s_{1}}, f_{s_{2}}\right\rangle\right\rangle$, en donde $i \leq s$ y $f_{i_{1}}$ y $f_{i_{2}}$ son miembros de $F_{i}$. A los pares de factores del mismo conjunto $F_{i}$ los llamamos componentes de genotipos, de forma tal que un componente de genotipo tiene la forma $\left\langle f_{i_{1}}, f_{i_{2}}\right\rangle$, en donde $i \leq s$ y $f_{i_{1}}$ y $f_{i_{2}}$ son miembros de $F_{i}$. Se tienen aquí nuevamente $s$ genotipos paternos, simbolizados por $\left\langle\gamma_{1_{1}}, \ldots, \gamma_{1_{s}}\right\rangle$ y $\left\langle\gamma_{2_{1}}, \ldots, \gamma_{2_{s}}\right\rangle$, y finitamente tantos genotipos para la descendencia como para que haya uno para cada fenotipo que ocurre: $\left\langle\gamma_{1_{1}}, \ldots, \gamma_{i_{j}}, \ldots, \gamma_{n_{s}}\right\rangle$.

(4) FEV representa un conjunto de parámetros, los factores evolutivos o fuerzas evolutivas (las "causas" de los cambios). En la literatura se suelen mencionar cuatro de tales factores (siendo así un conjunto con cardinalidad igual a cuatro), que son parámetros a ser considerados, ya que afectan, modificándolas, las distribuciones de genotipos en la descendencia. Si m, n, s, F simbolizan dichos parámetros, $m$ simboliza la migración, $n$ simboliza la mutación, $s$ simboliza la selección y $F$ simboliza la deriva génica, $F E V=\{m, n, s, F\}$.

(5) El tiempo es representado mediante un orden lineal $\langle T,<\rangle$, en donde se supone que $T$ es un conjunto finito, no vacío, de índices para generaciones (de poblaciones) que también pueden considerarse representando los puntos o períodos de tiempo ty $\langle T,<\rangle \subseteq T \times T$ es transitiva, anti-reflexiva y conectada. $t+1$ denota el punto o corto período de tiempo inmediatamente sucesor de $t$. En la interpretación de "generaciones", $t+1$ es el índice de la generación $I_{t+1}$ o $P O P_{t+1}$ inmediatemente sucesiva o siguiente a la generación con índice $t$.

Las funciones que ocurren en el predicado se interpretan por su parte del siguiente modo:

(6) APP ("appearance") le asigna a cada población, ya sea de los progenitores o de la descendencia, su fenotipo. Consiguientemente, las ecuaciones tienen la forma

$$
\begin{aligned}
& \operatorname{APP}\left(\operatorname{pop}_{1}\right)=\left\langle\pi_{1_{1}}, \ldots, \pi_{1_{k}}\right\rangle, \\
& \operatorname{APP}\left(\operatorname{pop}_{2}\right)=\left\langle\pi_{2_{1}}, \ldots, \pi_{2_{k}}\right\rangle, \\
& \operatorname{APP}\left(\operatorname{pop}_{n}\right)=\left\langle\pi_{1_{1}}, \ldots, \pi_{i_{j}}, \ldots, \pi_{n_{k}}\right\rangle(\text { en donde } i \leq n, j \leq k) .
\end{aligned}
$$

Principia, 12(2) (2008), pp. 121-54. 
(7) MAT ("mator") representa la transición de los padres a su descendencia. Le asigna conjuntos de conjuntos de individuos (conjuntos de poblaciones de descendencia) a ciertos pares de conjuntos de individuos (conjuntos de poblaciones paternas):

$\operatorname{MAT}\left(\mathbf{p o p}_{1}, \mathbf{p o p}_{2}\right)=\left\langle\operatorname{pop}_{1}, \ldots, \operatorname{pop}_{n}\right\rangle$, en donde el número $n$ varía de acuerdo con los progenitores.

Es una función de pares de conjuntos de individuos ( $\operatorname{pop}_{1}, \operatorname{pop}_{2}$ ) en un conjunto de conjuntos de individuos $\left(\operatorname{pop}_{1} \cup \ldots \cup \operatorname{pop}_{n}\right)$. Que MAT sea una función parcial significa que no necesita ser definida para todas las posibles combinaciones (esto es, también para pares $\left\langle\operatorname{pop}_{1}, \mathbf{p o p}_{2}\right\rangle$ que no se cruzan). Ahora el vínculo de una generación a la siguiente es establecido simplemente por tomar la última generación como consistente en la unión de todos los conjuntos de descendientes producidos por MAT a partir de pares en la primera población para los cuales está definida MAT (e.e. que producen descendencia). Escogemos que MAT no dependa del tiempo, porque, en cierto sentido, la escala temporal genéticamente relevante está determinada mediante dicha función MAT, si bien los individuos (poblaciones) que se cruzan pueden pertenecer a la misma generación o no, e.e. puede haber o no solapamiento entre las diferentes generaciones.

(8) Ya que las poblaciones en una generación pueden contener individuos de más de dos fenotipos, DIST (“distributor”) describe la transición de una distribución de fenotipos de una generación a otra distribución tal en la generación sucesiva. Que sea una función parcial significa que no necesita ser definida para pares $\left\langle\pi, \pi^{\prime}\right\rangle$ que corresponden a individuos de poblaciones que no se cruzan. La consideración cuantitativa de la distribución de fenotipos en la descendencia constituye el punto de partida de la genética. Las distribuciones de los fenotipos son proporcionadas por frecuencias relativas. ${ }^{11}$ Formalmente, una distribución es una función que asigna, a cada elemento de un conjunto dado, un número real, indicando el "peso" o "probabilidad de ocurrencia" de ese elemento. Este concepto es más estrecho que el de una distribución de probabilidades; por eso es que es llamado distribuciones genéticas o $\Gamma$-distribuciones de fenotipos $D(P),{ }^{12}$ que será proporcionado por la Definición auxiliar 4: el conjunto de todas las $\Gamma$-distribuciones sobre un conjunto $X$ se describe mediante $D(X)$; formalmente, miembros $\mathbf{p}$ de $D(P)$ son procesos genéticos estocásticos sobre $P$ con respecto a $T$; esto significa que $\mathrm{p}: T \times P \rightarrow \mathbb{R}$, es una función que le asigna números reales no-negativos a puntos de tiempo y fenotipos, tales que, para un índice de tiempo fijo $t$, 
$\mathrm{p}_{t}$ es una distribución genética, en donde $\mathrm{p}_{t}(\pi) \geq 0 \mathrm{y}$, para todo $\pi \in P$, $\sum_{\pi \in P} \mathbf{p}_{t}(\pi)=1$; DIST toma como argumentos a un conjunto de dichas funciones $\mathbf{p}_{t}(\pi)=\mathbf{p}(t, \pi)$ y asume como valores conjuntos de tales funciones en la generación siguiente; a menudo escribiremos tales distribuciones en la forma más conveniente $\sum_{r_{i}} \pi_{i}$, donde las $\pi_{i}$ varían en el conjunto $P$ y en donde $r_{i}$ es el valor de la función correspondiente de la distribución, e.e. $r_{i}=\mathbf{p}_{t}\left(\pi_{i}\right)$. Así, tenemos ecuaciones de la forma:

$\operatorname{DIST}\left(t,\left\langle\pi_{1_{1}}, \ldots, \pi_{1_{k}}\right\rangle,\left\langle\pi_{2_{1}}, \ldots, \pi_{2 k}\right\rangle\right)=\left\langle r_{1} \pi_{1_{1}}, \ldots, r_{j} \pi_{i_{j}}, \ldots, r_{k} \pi_{n_{k}}\right\rangle$ (en donde todas las $r_{i}$ son números reales positivos, tales que $\left.\sum_{1 \leq i \leq k} r_{i}=1\right)$.

En realidad, DIST no es un auténtico primitivo, ya que puede ser definido mediante MAT y APP. Definición auxiliar 5: comenzando con dos poblaciones paternas $\mathbf{p o p}_{1}$, $\mathbf{p o p}_{2}$, vemos el valor de $\mathrm{MAT}\left(\mathbf{p o p}_{1}, \mathbf{p o p}_{2}\right)$, e.e., el conjunto de la descendencia $\left\{\operatorname{pop}_{1}, \ldots\right.$, pop $\left._{n}\right\}$; determinamos el valor de $\operatorname{APP}\left(\mathbf{p o p}_{n}\right)$ para $i \leq n$, e.e., los fenotipos que ocurren en la descendencia; contamos tanto el número total $n$ de la descendencia como el número $m_{i}$ de la descendencia que muestra un fenotipo dado y calculamos la frecuencia relativa $r_{i}=m_{i} / n$ de ese fenotipo; la lista de todas las frecuencias relativas obtenidas para las distintas descendencias es así la distribución deseada de fenotipos en la descendencia de $\mathbf{p o p}_{1}$ y $\mathbf{p o p}_{2}$, esto es, el valor de DIST $\left(\mathbf{p o p}_{1}, \mathbf{p o p}_{2}\right)$. Esto proporciona una definición precisa de la distribución de fenotipos correspondiente, que puede ser evaluada entonces de manera mecánica para formas dadas de MAT y APP.

(9) DET ("determiner") es una función que asigna fenotipos a los genotipos. Que sea suprayectiva significa que es una función de $G$ en el conjunto $P$, en la que no hay elementos de $P$ que no sean asignados a $G$; es una función de G sobre P. Los genotipos determinan fenotipos, pero no sucede a la inversa, si bien un fenotipo puede ser determinado por varios genotipos distintos. Debido a esto es que han sido escogidos números diferentes: $k$ para el número de fenotipos y s para el número de genotipos, siendo $k$ normalmente menor o igual que $s$. Se tienen, para el caso de individuos, ecuaciones de la forma $\operatorname{DET}\left(\gamma_{i}\right)=\pi_{j}$, y, para el caso de poblaciones, ecuaciones de la forma $\operatorname{DET}\left(\left\langle\gamma_{1}, \ldots, \gamma_{s}\right\rangle\right)=\left\langle\pi_{1}, \ldots, \pi_{k}\right\rangle($ en donde $i \leq s, j \leq k) .{ }^{13}$

(10) COMB ("combinator") representa la transición de genotipos paternos a genotipos en la descendencia. Asigna a distribuciones de genotipos particulares cualesquiera combinaciones o mezclas (distribuciones) de genotipos de la descendencia. Una distribución de genotipos pudiera ser considerada 
como una distribución genética, i.e. como una función que asigna números ("pesos") a los genotipos (ver nota 12). Es una especie de análogo teórico de DIST. Al igual que en el caso de los fenotipos, también se necesita un elemento cuantitativo, probabilístico. Pero en vez de frecuencias relativas, se habla aquí de probabilidades propiamente dichas, ya que uno se encuentra en un nivel teórico, en donde los objetos en general no son directamente observados. La diferencia es, en ciertos aspectos, similar a la existente entre probabilidades experimentales y probabilidades esperadas (teóricas). Sin embargo, hay muchas aplicaciones donde las frecuencias relativas de experimentos previos son utilizadas como datos para la estimación de las probabilidades esperadas. Las distribuciones genéticas o $\Gamma$-distribuciones de genotipos, $D(G)$ ("probabilidades teóricas") son proporcionadas por la Definición auxiliar 6: aquí, los $\mathbf{p}^{*}$ de $D(G)$ son procesos genéticos estocásticos sobre $\mathrm{G}$ con respecto a $\mathrm{T}$ y al conjunto de parámetros $\mathrm{FEV}$. Esto significa que $\mathbf{p}^{*}: T \times G \times F E V \rightarrow \mathbb{R}$ es una función que le asigna números reales nonegativos a puntos de tiempo, genotipos y factores evolutivos, tales que, para un índice de tiempo fijo $t$, y factores evolutivos fijos fev (que pudieran ser alguno o varios de los mencionados: migración $m$, mutación $n$, selección $s$ o deriva génica $F), \mathbf{p}_{t, f e v}^{*}$ es una distribución genética, en donde $\mathbf{p}_{t, f e v}^{*}(\gamma) \geq 0$ y, para todo $\gamma \in G, \sum_{\gamma \in G} \mathbf{p}_{t, f e v}^{*}(\gamma)=1$. Aquí $\mathbf{p}_{t, f e v}^{*}$ es formalmente definida estableciendo $\mathbf{p}_{t, f e v}^{*}(\gamma)=\mathbf{p}^{*}(t, \gamma, f e v)$, tal que $\mathbf{p}_{t, f e v}^{*}: G \rightarrow \mathbb{R}$ tiene el tipo correcto para ser una $\Gamma$-distribución. $C O M B$ toma como argumentos a un conjunto de dichas funciones $\mathbf{p}_{t, f e v}^{*}(\gamma)=\mathrm{p}^{*}(t, \gamma, f e v)$ y asume como valores conjuntos de tales funciones en la generación siguiente. Así, tenemos ecuaciones de la forma:

$\operatorname{COMB}\left(t,\left\langle\alpha_{1} \gamma_{11}, \ldots, \alpha_{s} \gamma_{1 s}\right\rangle,\left\langle\alpha_{1} \gamma_{21}, \ldots, \alpha_{s} \gamma_{2 s}\right\rangle, m, n, s, F\right)=\left\langle\alpha_{1} \gamma_{11}, \ldots, \alpha_{j} \gamma_{i j}\right.$, $\left.\ldots, \alpha_{s} \gamma_{n s}\right\rangle$ (en donde todas las $\alpha_{i}$ son números reales positivos, tales que $\left.\sum_{1 \leq i \leq s} \alpha_{i}=1\right)$.

Los distintos objetos y funciones pueden representarse gráficamente del siguiente modo (ver Fig. 1), en donde los objetos son representados mediante rectángulos y las funciones mediante flechas.

\subsubsection{Los modelos de la genética clásica de poblaciones}

El conjunto de modelos de la genética clásica de poblaciones $\mathbf{M}(\mathrm{GCP})$ es un subconjunto de los modelos potenciales, cuyas estructuras satisfacen, además de los axiomas impropios, la ley fundamental de la genética clásica de poblaciones.

Principia, 12(2) (2008), pp. 121-54. 


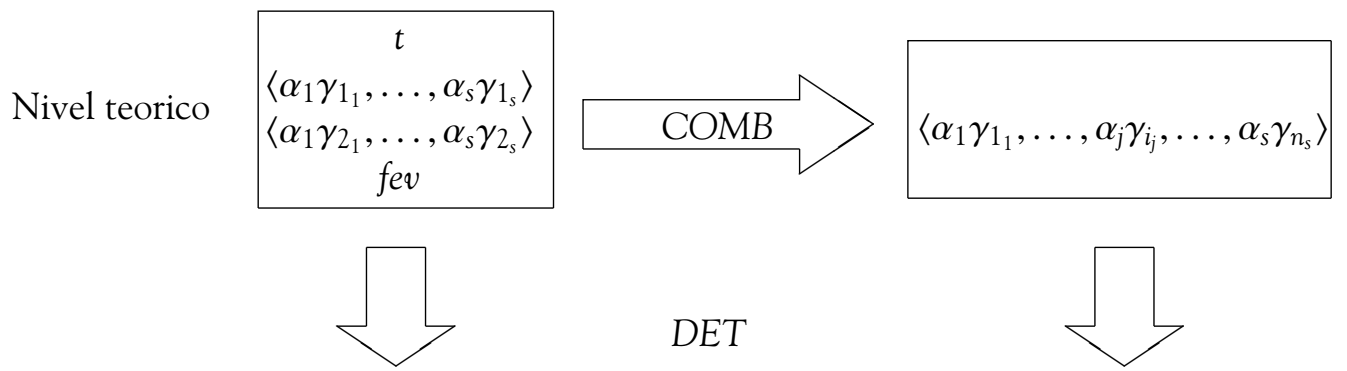

Nivel de la apariencia
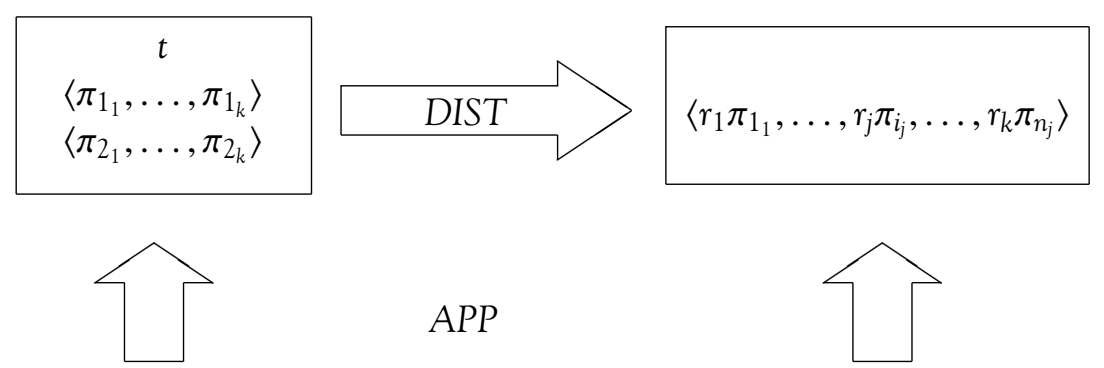

APP

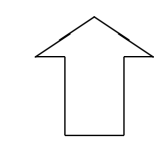

Nivel de los individuos (poblaciones)
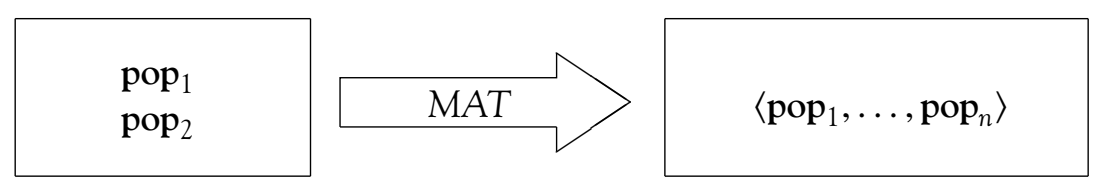

Figura 1:

Definición 2. $\mathrm{M}(\mathrm{GCP})$ : Si $x=\left\langle\mathrm{I},\left(\mathrm{C}_{i}\right)_{i \leq k},\left(\mathrm{~F}_{i}\right)_{i \leq}, \mathrm{FEV}, \mathrm{T},<, \mathrm{APP}, \mathrm{MAT}, \mathrm{DIST}\right.$, DET, $C O M B\rangle$ es un $\mathbf{M}_{\mathbf{p}}(\mathrm{GCP})$, entonces $x$ es una genética clásica de poblaciones $(x \in \mathbf{M}(\mathrm{GCP}))$ si y sólo si

(1) para toda pop, pop $^{\prime} \subseteq \operatorname{Pot}(I)$ tal que MAT esté definido para $\left\langle\right.$ pop, pop' p, $^{\prime}$ para toda $t \in T$, para toda $\left\langle\gamma_{1}, \ldots, \gamma_{s}\right\rangle,\left\langle\gamma_{1}^{\prime}, \ldots, \gamma_{s}^{\prime}\right\rangle \in \mathrm{G}$, para todo fev $\in$ FEV , tal que $\operatorname{DET}\left(\left\langle\gamma_{1}, \ldots, \gamma_{s}\right\rangle\right)=\operatorname{APP}($ pop $)$ y $\operatorname{DET}\left(\left\langle\gamma_{1}^{\prime}, \ldots, \gamma_{s}^{\prime}\right\rangle\right)=$ $\operatorname{APP}\left(\right.$ pop $\left.^{\prime}\right)$ :

$\operatorname{COMB}\left(t,\left\langle\alpha_{1} \gamma_{11}, \ldots, \alpha_{s} \gamma_{1 s}\right\rangle,\left\langle\alpha_{1} \gamma_{21}, \ldots, \alpha_{s} \gamma_{2 s}\right\rangle\right.$, fev $)=$

$$
\operatorname{DIST}\left(\operatorname{DET}\left(\left\langle\gamma_{1}, \ldots, \gamma_{s}\right\rangle\right), \operatorname{DET}\left(\left\langle\gamma_{1}^{\prime}, \ldots, \gamma_{s}^{\prime}\right\rangle\right)\right)
$$

o, alternativamente, y recordando que DIST puede ser definido por medio de MAT y de APP:

$\operatorname{COMB}\left(t,\left\langle\alpha_{1} \gamma_{11}, \ldots, \alpha_{s} \gamma_{1 s}\right\rangle,\left\langle\alpha_{1} \gamma_{21}, \ldots, \alpha_{s} \gamma_{2 s}\right\rangle\right.$, fev $)=$

$\operatorname{APP}\left(\operatorname{MAT}\left(\left\langle p o p, p o p^{\prime}\right\rangle\right)\right)$

El axioma (1) formula la ley fundamental de la genética clásica de poblaciones, Principia, 12(2) (2008), pp. 121-54. 
la "ley de concordancia poblacional". Ésta establece que

- dadas poblaciones - con cierta distribución de características (fenotipos) y cierta distribución de factores o genes (genotipos) y en donde se da cierta relación entre características (fenotipos) y genes (genotipos) -

- que se cruzan y dejan descendencia (generaciones siguientes) - que posee cierta distribución de características (fenotipos) y cierta distribución de genes (genotipos), y en donde se da cierta relación entre características (fenotipos) y genes (genotipos) —,

- tiene lugar cierta concordancia (exacta o aproximada) entre las distribuciones de las características (fenotipos) (frecuencias relativas) y las distribuciones de genes (genotipos) postuladas teóricamente (probabilidades esperadas o teóricas) en la descendencia (generaciones siguientes), dadas determinadas relaciones entre genes (genotipos) y características (fenotipos) (de expresión de genes con distintos grados de dominancia o epistasis).

A fin de lograr una comprensión cabal de esta ley, consideremos dos poblaciones parentales pop, pop $^{\prime}$, con fenotipos $\left\langle\pi_{1}, \ldots, \pi_{n}\right\rangle,\left\langle\pi_{1}^{\prime}, \ldots, \pi_{n}^{\prime}\right\rangle$, genotipos $\left\langle\gamma_{1}, \ldots, \gamma_{s}\right\rangle,\left\langle\gamma_{1}^{\prime}, \ldots, \gamma_{s}^{\prime}\right\rangle$, factores evolutivos fev y las distribuciones genéticas correspondientes sobre fenotipos y genotipos en su descendencia: $D(P)=$ $\left\langle r_{1} \pi_{11}, \ldots, r_{j} \pi_{i j}, \ldots, r_{k} \pi_{n k}\right\rangle, D(G)=\left\langle\alpha_{1} \gamma_{11}, \ldots, \alpha_{j} \gamma_{i j}, \ldots, \alpha_{s} \gamma_{n s}\right\rangle$. Veamos primero el caso más simple, en donde DET es uno-a-uno. En este caso cada fenotipo $\pi_{j}$ proviene de exactamente uno de los genotipos $\gamma_{1}, \ldots, \gamma_{s}$. De este modo $k=s \mathrm{y}$ asumiríamos que cada $\pi_{j}$ es producido por $\gamma_{j}$. La noción natural de concordancia entre dos distribuciones $\left\langle r_{1} \pi_{11}, \ldots, r_{j} \pi_{i j}, \ldots, r_{k} \pi_{n k}\right\rangle,\left\langle\alpha_{1} \gamma_{11}, \ldots, \alpha_{j} \gamma_{i j}, \ldots, \alpha_{s} \gamma_{n s}\right\rangle$ es la siguiente. Decimos que $D(P)$ y $D(G)$ concuerdan idealmente la una con la otra si y sólo si, para toda $j \leq s: r_{j}=\alpha_{j}$.

En general, la situación no es tan simple, ya que algunos fenotipos suelen ser producidos por varios genotipos distintos, o sea $k<s$. En estos casos tenemos que comparar las probabilidades de todos esos genotipos con la frecuencia relativa del fenotipo que ellos producen. Formalmente, introduzcamos, para genotipos parentales dados $\left\langle\gamma_{1}, \ldots, \gamma_{s}\right\rangle,\left\langle\gamma_{1}^{\prime}, \ldots, \gamma_{s}^{\prime}\right\rangle$ e índice dado $j \leq k$, el conjunto $\mathrm{C}\left(\left\langle\gamma_{1}, \ldots, \gamma_{s}\right\rangle,\left\langle\gamma_{1}^{\prime}, \ldots, \gamma_{s}^{\prime}\right\rangle, \mathrm{j}\right)$ de todas las probabilidades $\alpha_{i}$ que ocurren en $\mathrm{D}(\mathrm{G})$ tal que el correspondiente genotipo $\gamma_{i}$ produce el fenotipo $\pi_{j}$ (ver Fig. 2). Más aún, escribamos $c_{j}=\sum \alpha_{i}, i \in \mathrm{C}\left(\left\langle\gamma_{1}, \ldots, \gamma_{s}\right\rangle,\left\langle\gamma_{1}^{\prime}, \ldots, \gamma_{s}^{\prime}\right\rangle, j\right)$, para la suma de todas esas probabilidades $\alpha_{i}$ cuyos correspondientes genotipos $\gamma_{i}$ den lugar al mismo fenotipo $\pi_{j}$ con frecuencia relativa $r_{j}$. 


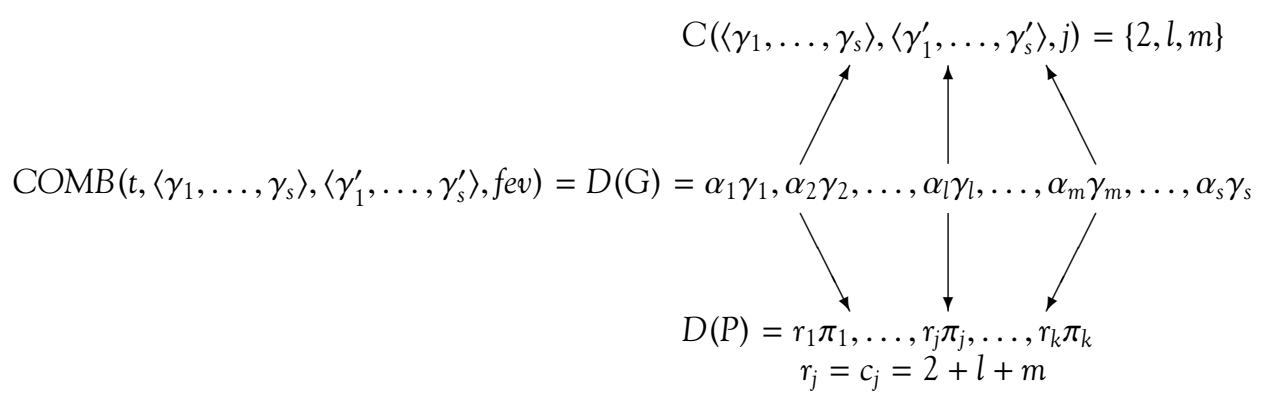

Figura 2:

A fin de poder determinar si $D(P)$ y $D(G)$ concuerdan, debemos comparar entonces cada frecuencia relativa $\pi_{j}$ con la suma $c_{j}$. Decimos que, en el caso general, $D(P)$ y $D(G)$ concuerdan idealmente si y sólo si, para toda $j \leq k: r_{j}=c_{j}$.

Dos distribuciones genéticas de genotipos $\left\langle\alpha_{1} \gamma_{11}, \ldots, \alpha_{j} \gamma_{i j}, \ldots, \alpha_{s} \gamma_{n s}\right\rangle$ y de fenotipos $\left\langle r_{1} \pi_{11}, \ldots, r_{j} \pi_{i j}, \ldots, r_{k} \pi_{n k}\right\rangle$ concuerdan idealmente la una con la otra, si y sólo si:

(i) $k \leq s$,

(ii) cada fenotipo $\pi_{j}$ se obtiene, mediante DET, de un genotipo $\gamma_{i}$ o de más genotipos diferentes $\gamma_{i}, \mathrm{y}$

(iii) los coeficientes de probabilidad de los ítems relacionados en (ii) concuerdan los unos con los otros.

Este axioma conecta de un modo inseparable los términos primitivos más importantes de GCP en una "gran" fórmula. Esta característica puramente sintáctica distingue (1), la "ley de concordancia poblacional", como una ley sinóptica, de hecho, la ley sinóptica de GCP. Allí figuran tanto los propios o distintivos de la genética, los genético-teóricos - los conjuntos de los factores o genes (genotipo), el conjunto de factores evolutivos, las distribuciones de probabilidad de los genes en la descendencia y las relaciones postuladas entre los genes y las características - como los que no lo son, los genético-no-teóricos, más accesibles empíricamente - los individuos (progenitores y descendientes) y poblaciones (progenitoras y descendientes), el conjunto de las características, la asignación de características a los individuos y a las poblaciones y de descendientes a los progenitores y las frecuencias relativas de las características observadas en la descendencia. Más aún, podríamos afirmar que esta ley fue aceptada implícitamente como válida en todas las aplicaciones de la teoría por la comunidad de genetistas de 
poblaciones, que la tuvo como trasfondo general a partir del cual llevar a cabo análisis particulares de las distintas distribuciones de características encontradas, proporcionándoles así una guía para la investigación y el tratamiento específico de esas diversas situaciones empíricas. El rol primario de la ley de concordancia poblacional fue el de guiar el proceso de especialización, determinando los modos en que ella se debe especificar para obtener leyes especiales. La presencia de estos elementos en la ley de concordancia poblacional justifican entonces que ésta pueda ser vista como la ley fundamental de la genética clásica de poblaciones.

\subsubsection{Los modelos parciales de la genética clásica de poblaciones}

La clase de los modelos parciales $\mathbf{M}_{\mathrm{pp}}$ está constituida por aquello que se pretende sistematizar, explicar y predecir. Para poder caracterizar esta clase es necesario establecer la distinción entre conceptos teóricos y conceptos no-teóricos en el interior de dicha teoría, es decir, entre conceptos específicos de la genética (o GCP-teóricos) y no específicos de la genética (o GCP-no-teóricos). Intuitivamente, y de acuerdo con el criterio el criterio de T-teoricidad ${ }_{1}$ introducido más arriba, un concepto es teórico para la teoría considerada (en este caso, GCP), si su extensión sólo puede ser determinada presuponiendo las leyes de GCP (e.e. los modelos de GCP); la determinación del concepto sólo funciona en situaciones en las que se satisface la ley fundamental de GCP. De otro modo, el concepto será GCP-no-teórico.

Examinemos los conceptos básicos de GCP, a saber: $I,\left(C_{i}\right)_{i \leq k},\left(F_{i}\right)_{i \leq s}, F E V$, T, <, APP, MAT, DIST, DET, COMB, a fines de determinar cuáles son GCP. teóricos y cuáles GCP-no-teóricos.

Comencemos con I. Este concepto representa un conjunto de individuos, que se cruzan y, de este modo, producen descendencia. Constituye uno de los conjuntos básicos principales que establecen la ontología de la teoría. Sin embargo, no parece que para averiguar si un individuo particular $i$ pertenece al conjunto I sea necesario presuponer la validez de GCP; bastarían, de hecho, métodos empíricos independientes. Lo mismo podría decirse del conjunto de poblaciones, definido sobre la base del conjunto de individuos.

Algo similar ocurre con el conjunto $\left(C_{i}\right)_{i \leq k}$ de tipos de características, que constituye otro de los conjuntos básicos principales que establecen la ontología de la teoría: las características (sus expresiones o rasgos) se determinan empíricamente, con independencia de la ley fundamental de GCP.

Continuemos con los componentes T, <, APP, MAT, DIST, DET y COMB, dejando para más adelante el análisis del conjunto de parámetros FEV y del con-

Principia, 12(2) (2008), pp. 121-54. 
junto de tipos de factores $\left(F_{i}\right)_{i \leq s}$. El tiempo, representado mediante un orden lineal $\langle T,<\rangle$ de índices para generaciones (de poblaciones), puede ser determinado mediante métodos genético de poblaciones-independientes. APP, por su parte, es una función que le asigna a cada población pop su fenotipo y se determina empíricamente, independientemente de si se aplica(n) o no la(s) ley(es) de la genética. Lo mismo ocurre con MAT, que le asigna a dos poblaciones paternas cualesquiera que se cruzan su descendencia. DIST, a su vez, es una función que describe la transición de una distribución de fenotipos de una generación a otra distribución de fenotipos en la generación sucesiva. Dicha función no constituye un auténtico concepto primitivo, sino que se define en función de MAT y APP; sus coeficientes $r_{j}$ se pueden construir así a partir de los datos empíricos de la distribución, tal como aparece en la definición de esa función: a través de MAT y APP, aplicadas a las poblaciones y a los fenotipos. De este modo, se puede decir que APP, MAT y DIST son funciones GCP-no-teóricas.

Veamos ahora qué ocurre con las funciones DET y COMB. DET es una función que asigna fenotipos a los genotipos, mientras que la segunda es una función que representa la transición de genotipos paternos a genotipos en la descendencia, asignándole a distribuciones de genotipos particulares cualesquiera combinaciones (distribuciones) de genotipos de la descendencia con cierta probabilidad de ocurrencia. Recordemos que la ley fundamental de la genética de poblaciones tiene la forma de una concordancia: los dos coeficientes que al final se comparan, $r_{j}$ y $\alpha_{j}$ o, de modo más general, $r_{j}$ y $c_{j}$, se construyen en primer término de manera independiente el uno del otro. Vimos que los coeficientes $r_{i}$ de DIST se construyen a partir de MAT y APP, quedando la función determinada así empíricamente. Para construir $\alpha_{j}$ o $c_{j}$ se necesitan dos funciones: primero, COMB, para hacer la distribución (teórica) de genotipos; segundo, DET, para determinar, en caso de que $k=s$ y que cada $\pi_{j}$ es producido por $\gamma_{j}$, que $r_{j}=\alpha_{j}$, o, en caso que algunos fenotipos suelen ser producidos por varios genotipos distintos, o sea $k<s$, el conjunto $\mathrm{C}\left(\left\langle\gamma_{1}, \ldots, \gamma_{s}\right\rangle,\left\langle\gamma_{1}^{\prime}, \ldots, \gamma_{s}^{\prime}\right\rangle, j\right)$ sobre COMB (siendo $\mathrm{C}\left(\left\langle\gamma_{1}, \ldots, \gamma_{s}\right\rangle,\left\langle\gamma_{1}^{\prime}, \ldots, \gamma_{s}^{\prime}\right\rangle, j\right)$ el conjunto de todas las probabilidades $\alpha_{i}$ que ocurren en $D(\mathrm{G})$ tal que el correspondiente genotipo $\gamma_{i}$ produce el fenotipo $\pi_{j} \mathrm{y}$ $c_{j}=\sum \alpha_{i}, i \in \mathrm{C}\left(\left\langle\gamma_{1}, \ldots, \gamma_{s}\right\rangle,\left\langle\gamma_{1}^{\prime}, \ldots, \gamma_{s}^{\prime}\right\rangle, j\right)$, e.e. la suma de todas esas probabilidades $\alpha_{i}$ cuyos correspondientes genotipos $\gamma_{i}$ dan lugar al mismo fenotipo $\pi_{j}$ con frecuencia relativa $r_{j}$ ). Ambas constituyen hipótesis: sobre el modo en que se relacionan los genotipos con los fenotipos DET y sobre los posibles genotipos que pudieran corresponder a un fenotipo determinado COMB. Sin embargo, la corrección de esas hipótesis es algo que se prueba con la aplicación de (la ley de fundamental de) GCP, ya que, en tanto que la concordancia parte de $r_{j}, \alpha_{j}$ o $c_{j}$

Principia, 12(2) (2008), pp. 121-54. 
es igual a $r_{j}$ en la medida en que la construcción de esos coeficientes sea correcta. Por ello, DET y COMB tienen que ser consideradas GCP-teóricas.

El caso del conjunto $\left(F_{i}\right)_{i \leq s}$ debe ser considerado con detenimiento. $\left(F_{i}\right)_{i \leq s}$ representa el conjunto de tipos de factores, e.e. de aquellas entidades teóricas que se proponen como responsables de la aparición de fenotipos determinados. Cuántos pares de (eventualmente) distintos tipos de factores hay también pertenece a la hipótesis sobre la que está construida COMB. Si una hipótesis de este tipo no satisface la ley, es posible que el motivo de ello sea un número o tipo inadecuado de factores o genotipos. Por ello, podemos afirmar que también el conjunto $\left(F_{i}\right)_{i \leq s}$ presupone la ley fundamental en su determinación y deben ser considerados como GCP-teóricos, a pesar de que los conceptos teóricos no suelen aparecer en los conjuntos básicos y los distintos criterios de teoricidad propuestos a partir de la concepción estructuralista están pensados fundamentalmente para funciones (sin embargo, la determinación del número y tipos de factores o genotipos en los individuos, y no en las poblaciones, se puede efectuar mediante la genética clásica).

En relación con el conjunto de parámetros FEV, que representan los "factores evolutivos" (migración, mutación, selección y deriva génica), parecería que vinieran dados por campos afines y relacionados con la genética clásica de poblaciones, tales como la genética (clásica o molecular) y la teoría de la evolución, aunque las hipótesis respecto de su ocurrencia en la genética clásica de poblaciones pueden ser sometidas a prueba mediante la contrastación de las aserciones empíricas asociadas a las especializaciones terminales de la ley fundamental de dicha teoría y, de este modo, también tener determinaciones de sus extensiones genético de poblaciones-dependientes. Es por ello que este conjunto de parámetros FEV sería GCP-teórico de acuerdo con el criterio de $\mathrm{T}$-teoricidad 2 , pero GCP-no-teórico, según el criterio de T-teoricidad ${ }_{1}$. Aquí, sin embargo, debido a que parecería que los datos de los cuales la teoría pretende dar cuenta no contienen información acerca de tales parámetros y éstos, más bien, son introducidos para dar cuenta de ellos, vamos a utilizar el criterio de $\mathbf{T}$-teoricidad 2 .

Ahora estamos en condiciones de caracterizar la clase de los modelos parciales de GCP del siguiente modo:

Definición 3. $\mathbf{M}_{p p}(\mathrm{GCP}): y=\left\langle I,\left(C_{i}\right)_{i \leq k}, T,<, A P P, M A T, D I S T\right\rangle$ es una genética clásica de poblaciones parcial $\left(y \in \mathbf{M}_{p p}(\mathrm{GCP})\right)$ si y sólo si existe una $x$ tal que

(1) $x=\left\langle I,\left(C_{i}\right)_{i \leq k},\left(F_{i}\right)_{i \leq s}, F E V, T,<, A P P, M A T, D I S T, D E T, C O M B\right\rangle$ es un $\mathrm{M}_{\mathrm{p}}(\mathrm{GCP})$

(2) $y=\left\langle\mathrm{I},\left(\mathrm{C}_{i}\right)_{i \leq k}, \mathrm{~T},<, \mathrm{APP}, \mathrm{MAT}, \mathrm{DIST}\right\rangle$

Principia, 12(2) (2008), pp. 121-54. 


\subsubsection{Condiciones de ligadura para la genética clásica de poblaciones}

Las condiciones de ligadura de la genética clásica de poblaciones $\mathrm{C}(\mathrm{GCP})$ son relaciones del tipo de las denominadas de igualdad. En general, las condiciones de ligadura de igualdad funcionan del siguiente modo. Se considera alguna función, que representa una propiedad de los objetos de la teoría. La condición de ligadura de igualdad para esa función requiere, entonces, que los objetos que ocurran en aplicaciones distintas posean el mismo valor en todas esas aplicaciones.

En uno de los casos, se trata de la exigencia de que si un individuo ocurre en distintas generaciones, mantiene su fenotipo. Se utiliza aquí el símbolo "C" (por "condición de ligadura") y las siguientes convenciones: si $x$ es un elemento del conjunto de modelos potenciales de GCP de la generación $t$ e y es un elemento del conjunto de modelos potenciales de GCP de alguna generación sucesora $t+n$, entonces los componentes pertenecientes a ellos deberían tener " $x$ " o " $y$ " como subíndices. El conjunto de individuos del modelo potencial $x$ se simboliza por " $I_{x}$ ", la función APP de y por $A P P_{y}$, etc. Para dicha condición de ligadura es escogida la simbolización " $\mathrm{C}_{\mathrm{APP}}^{(\approx,=\rangle}$. El subíndice indica la función de la que se trata, a saber: la función APP; y el supraíndice simboliza el tipo de condición de ligadura, a saber: de igualdad. Dicha condición de ligadura se expresa de la siguiente manera:

Definición 4. $\mathrm{C}_{1}(\mathrm{GCP})$ : la condición de ligadura de igualdad $\mathrm{C}_{\mathrm{APP}}^{\langle\approx}$ para $A P P$ está definida por $X \in \mathrm{C}_{A P P}^{(\approx,=\rangle}$ si y sólo si $X \subseteq \mathbf{M}_{\mathrm{p}}(\mathrm{GCP})$ y para toda $x, y \in X$ y toda $i$, si $i \in I_{x} \cap I_{y}$, entonces $\operatorname{APP}_{x}(i)=\operatorname{APP}_{y}(i)$.

En otro de los casos, la exigencia es que si un genotipo ocurre en distintas generaciones, su correspondiente fenotipo, dado por DET, también permanece idéntico. Como más arriba, aquí se utiliza el símbolo "C" (por "condición de ligadura") y las siguientes convenciones: si $x$ es un elemento del conjunto de modelos potenciales de GCP de la generación $t$ e $y$ es un elemento del conjunto de modelos potenciales de GCP de alguna generación sucesora $t+n$, entonces los componentes pertenecientes a ellos deberían tener " $x$ " o " $y$ " como subíndices. El conjunto de genotipos del modelo potencial $x$ se simboliza por " $\mathrm{G}_{x}$ ", la función DET de y por $\mathrm{DET}_{y}$, etc. Para dicha condición de ligadura es escogida la simbolización " $\mathrm{C}_{D E T}^{\langle\approx,=\rangle}$. El subíndice indica la función de la que se trata, a saber: la función DET; y el supraíndice simboliza el tipo de condición de ligadura, a saber: de igualdad. Dicha condición de ligadura se expresa de la siguiente manera:

Definición 5. $\mathrm{C}_{2}(\mathrm{GCP})$ : la condición de ligadura de igualdad $\mathrm{C}_{\mathrm{DET}}^{<\approx=>}$ para DET está definida por $X \in \mathrm{C}_{D E T}^{(\approx,=\rangle}$ si y sólo si $X \subseteq \mathbf{M}_{\mathrm{p}}(\mathrm{GCP})$ y para toda $x, y \in X$ y toda $\gamma$, si $\gamma \in \mathrm{G}_{x} \cap \mathrm{G}_{y}$, entonces $\operatorname{DET}_{x}(\gamma)=\operatorname{DET}_{y}(\gamma)$.

Principia, 12(2) (2008), pp. 121-54. 
La condición de ligadura global de la genética clásica de poblaciones (C(GCP)) es la unión de las condiciones de ligadura de igualdad recién presentadas.

\section{Definición 6. $\mathrm{C}(\mathrm{GCP})=\mathrm{C}_{1}(\mathrm{GCP}) \cup \mathrm{C}_{2}(\mathrm{GCP})$.}

En una reconstrucción verdaderamente completa de GCP deberíamos incluir los vínculos que esta teoría tiene con otras teorías (subyacentes). Sin embargo, ya que en este artículo dejamos abierta la cuestión de los vínculos esenciales de GCP con otras teorías y no profundizamos en su tratamiento, asumiendo idealmente que no hay tales vínculos, el núcleo teórico de la genética clásica de poblaciones $(\mathrm{K}(\mathrm{GCP}))$ puede ser caracterizado como sigue:

Definición 7. $\mathrm{K}(\mathrm{GCP})=\left\langle\mathrm{M}_{\mathrm{p}}(\mathrm{GCP}), \mathrm{M}(\mathrm{GCP}), \mathrm{M}_{p p}(\mathrm{GCP}), \mathrm{C}(\mathrm{GCP})\right\rangle$.

\subsubsection{Las aplicaciones intencionales de la genética clásica de poblaciones}

El dominio de aplicaciones intencionales I constituye la clase de aquellos sistemas empíricos a los que uno desea aplicar la ley fundamental de la teoría. Ellos no pueden ser caracterizados por medios puramente formales. Lo único que podemos decir desde un punto de vista formal es que una aplicación intencional es un modelo parcial. En nuestro caso, esto significa que $\mathrm{I}(\mathrm{GCP}) \subseteq \mathrm{M}_{p p}(\mathrm{GCP})$ y que los miembros de $\mathbf{I}(\mathrm{GCP})$ - a los que uno desea aplicar la ley fundamental de concordancia - son sistemas empíricos que contienen poblaciones con una cierta apariencia (es decir, con ciertas distribuciones de características o rasgos de ellas) que se cruzan, produciendo una descendencia, en la que los distintos rasgos de las distintas características ocurren en ciertas frecuencias relativas.

El elemento teórico básico de la genética clásica de poblaciones (T(GCP)) puede ahora ser caracterizado como sigue:

Definición 8. $\mathrm{T}(\mathrm{GCP})=\langle\mathrm{K}(\mathrm{GCP}), \mathrm{I}(\mathrm{GCP})\rangle$.

\subsubsection{La aserción empírica de la genética clásica de poblaciones}

La genética de poblaciones pretende que ciertos sistemas empíricos, descritos genética-no teóricamente, satisfacen las condiciones impuestas por ella en el siguiente sentido: esos son los datos de la experiencia que se deberían obtener, si la realidad se comportara como ella dice. Esta pretensión se expresa en la aserción empírica de la genética clásica de poblaciones, que puede formularse de la siguiente manera:

Principia, 12(2) (2008), pp. 121-54. 
(I) Todo sistema propuesto dado puede ser, añadiendo un conjunto de componentes teóricos $\left(F_{i}\right)_{i \leq s}, F E V, D E T$ y COMB a la parte no-teórica del núcleo teórico correspondiente $\left(\left\langle I,\left(C_{i}\right)_{i \leq k}, T,<, A P P, M A T, D I S T\right\rangle\right)$, aproximadamente extendido a, o incrustado en, un modelo de GCP, que también cumpla con las condiciones de ligadura $\mathrm{C}(\mathrm{GCP})$.

Esta afirmación puede ser trivial, si las condiciones impuestas a los componentes teóricos por el núcleo teórico son débiles. Pero no por ello debe rechazarse el núcleo teórico como trivial. Este núcleo teórico sirve como núcleo teórico básico para todas las aplicaciones propuestas de la genética clásica de poblaciones. Afirmaciones interesantes, no triviales, pueden ser obtenidas incorporando restricciones adicionales a través de las llamadas "especializaciones".

\subsection{Las especializaciones de la genética clásica de poblaciones}

Hay distintos modos posibles de especializar a la genética clásica de poblaciones. Las especializaciones consisten en especificaciones

a) del número $s$ de genotipos compuestos,

b) de la forma matemática concreta que asumiría DET,

c) del número de factores evolutivos FEV,

d) de la naturaleza de los factores evolutivos (si migración, mutación, selección y/o deriva génica),

e) de la forma matemática concreta que asumiría COMB.

Las diversas posibilidades de especialización pueden ser realizadas parcial o totalmente, de manera aislada o conjuntamente. Cada especificación establecería condiciones que, frente a ciertas situaciones o sistemas particulares considerados, podrían ser calificadas como de "más realistas". Una especialización en la que los cinco tipos de especificación hayan sido realizados totalmente se denomina "especialización terminal". Y, como ya se señaló en la nota 7, son las "aserciones empíricas" asociadas a dichas especializaciones las que en todo caso serían contrastadas y evaluadas, e.e. aceptadas o rechazadas, por constatar, o no, que los sistemas empíricos considerados cumplen con lo planteado por las especializaciones terminales propuestas.

\subsubsection{La ley de Hardy-Weinberg como especialización no-terminal}

A partir de la explicitación de la estructura de la genética clásica de poblaciones - e.e. de la reconstrucción de su elemento teórico básico y del señalamiento de

Principia, 12(2) (2008), pp. 121-54. 
las distintas maneras en que dicho elemento teórico puede ser especializado-, nos encontramos en condiciones de analizar el status de la ley de Hardy-Weinberg en el marco de dicha teoría. Recordemos que esta ley establece que, si se considera un único gen con sólo dos alelos, A y $a$, se puede demostrar matemáticamente que, si se cumplen ciertas condiciones (a saber: que los organismos de la población sean diploides, que la reproducción sea sexual, que las generaciones no se superpongan, que el cruzamiento o apareamiento entre individuos sea azaroso o aleatorio, que el tamaño de la población sea lo suficientemente grande como para que se apliquen las leyes de la probabilidad y que no haya factores evolutivos interviniendo, e.e. que la deriva génica, la migración y la mutación sean negligibles o puedan ser ignoradas y que la selección natural no afecte a los alelos en cuestión), entonces las frecuencias, o proporciones relativas, de los alelos A y $a$ en la población no cambiarán de una generación a otra, luego de la segunda generación. O sea, que el reservorio génico estará en un estado estacionario en un equilibrio- con respecto a estos alelos. En nuestra notación, esto último sería expresado del siguiente modo: para toda $a_{1} a_{2}$ y para toda $t+n$, se cumple $\mathbf{p}_{t+1}^{*}=\mathbf{p}_{t+n}^{*}$, en donde $a_{1} a_{2}$ representa a los alelos $A$ y $a$ en cuestión, $\mathbf{p}_{t+1}^{*}$ representa las frecuencias, o proporciones relativas, de los alelos alcanzadas en la primera generación siguiente al momento en que se efectúa el cruzamiento y $\mathbf{p}_{t+n}^{*}$ representa las frecuencias, o proporciones relativas, de los alelos en las generaciones siguientes. La ley de Hardy-Weinberg es, como puede apreciarse, una especie de "ley teórica (pura)", que sólo nos dice qué ocurre en el nivel de los factores alelos, genes o genotipos, pero que no dice nada acerca de cómo conectar dicho nivel con el de "la experiencia", "lo empírico", o sea, con los rasgos, características o fenotipos. Y lo mismo ocurre con sus formulaciones más generales, para más de dos alelos, para casos de poliploidía (organismos que tienen más de dos copias de cada cromosoma) y para la consideración conjunta de casos de alelos múltiples y poliploidía (ver nota 1$)$.

De hecho, si partimos de la "ley de concordancia poblacional" expuesta más arriba, y llevamos a cabo especificaciones adecuadas del tipo a), c), d) y e), obtenemos la ley de Hardy-Weinberg. Así, si

1) el número $s$ de genotipos compuestos se limita a 1 (especificación tipo a)

2) no hay factores evolutivos actuando (especificación tipo c y d)

3) $\left.\operatorname{COMB}\left(\left\langle\mathbf{p}_{t}^{*} a_{1} a_{2}\right\rangle,\left\langle\mathbf{p}_{t}^{*} a_{2} a_{1}\right\rangle, \emptyset\right\rangle\right)=\left(\left\langle\mathbf{p}_{t+1}^{*} a_{1} a_{1}+\mathbf{p}_{t+1}^{*} a_{1} a_{2}+\mathbf{p}_{t+1}^{*} a_{2} a_{1}+\mathbf{p}_{t+1}^{*} a_{2} a_{2}\right\rangle\right)$ (especificación tipo e)

Entonces para toda $a_{1} a_{2}$ y para toda $t+n: \mathbf{p}_{t+1}^{*}=\mathbf{p}_{t+n}^{*}$.

Principia, 12(2) (2008), pp. 121-54. 
De este modo, su "deducción" sólo tiene lugar si se añaden una serie de supuestos (premisas) adicionales. Además, en dicha "deducción" no son llevadas a cabo todas las especificaciones; en particular, no se especifica el modo en que los factores se vinculan con las características (e.e. no se especifica la forma matemática concreta que asumiría DET — especificación de tipo b-), razón por la cual, si bien es una especialización, la ley de Hardy-Weinberg no puede ser considerada una "especialización terminal". Más aún, en esta ley no encontramos ninguna de las condiciones necesarias o "síntomas" señalados en la sección 3 (a saber: tener carácter sinóptico, validez en todas las aplicaciones intencionales de la teoría, carácter cuasi-vacuo y papel sistematizador). De este modo, está claro que la ley de Hardy-Weinberg no podría ser considerada la ley fundamental de la genética clásica de poblaciones.

\section{A modo de conclusión}

El análisis realizado a partir de la reconstrucción estructuralista de la genética clásica de poblaciones, con la consiguiente identificación de la ley fundamental de dicha teoría, la "ley de concordancia poblacional", y de la caracterización de la ley de Hardy-Weinberg como una especialización no-terminal, permite recuperar los elementos señalados por Bas van Fraassen en su diagnóstico. En particular, permite entender mejor en qué sentido dicha ley no puede ser considerada una ley a ser utilizada como un axioma (o ley fundamental) de la genética clásica de poblaciones, pues es una ley de equilibrio que sólo vale bajos ciertas condiciones especiales, que sólo determina una subclase de modelos, cuya generalización (en realidad, cuya ley fundamental) resulta siendo vacua (condición 3 - carácter cuasi-vacuo o empíricamente irrestricto- de la sección 3) y que variantes complejas de la ley fundamental (y de la ley de Hardy-Weinberg) pueden (también) ser "deducidas" (en realidad, obtenidas mediante "especializaciones" distintas) para supuestos más realistas (condición 4 —carácter sistematizador- de la sección 3). Pero nuestro análisis no sólo permite entender mejor el status de la ley de Hardy-Weinberg en la genética clásica de poblaciones, sino que también posibilita tener una visión unificada de los distintos modelos, realmente heterogéneos, de (una y la misma teoría) la genética clásica de poblaciones (obtenidos todos por especialización de un mismo elemento teórico básico), y proporcionar herramientas que permitan avanzar en el análisis de las relaciones entre la genética clásica de poblaciones y la teoría de la evolución, y, así, en el análisis de esta última. Este último camino, que esperamos que sea transitado, o nosotros mismos transitar, próximamente, excede, sin embargo, los límites del presente trabajo.

Principia, 12(2) (2008), pp. 121-54. 


\section{Referencias}

Balzer, W. 1985a. Theorie und Messung. Springer: Berlin.

—. 1985b. On a New Definition of Theoreticity. Dialectica 39: 127-45.

—. 1986. Theoretical Terms: A New Perspective. The Journal of Philosophy 83(2): 7190.

—. 1996. Theoretical Terms: Recent Developments. In Balzer, W. \& Moulines, C.U. (eds) Structuralist Theory of Science: Focal Issues, New Results. Berlin: de Gruyter.

Balzer, W. \& Dawe, C.M. 1990. Models for Genetics. München: Institut für Philosophie, Logik und Wissenschaftstheorie.

Balzer, W. \& Lorenzano, P. 2000. The Logical Structure of Classical Genetics. Zeitschrift für allgemeine Wissenschaftstheorie 31: 243-66.

Balzer, W., Moulines, C. U. \& Sneed, J. 1987. An Architectonic for Science. The Structuralist Program. Dordrecht: Reidel.

Bauer, H. 1974. Wahrscheinlichkeitstheorie und Maßtheorie. Berlin: Walter de Gruyter. \& Co., $2 \mathrm{a}$ ed.

Beatty, J. 1980. Optimal-Design Models and the Strategy of Model Building in Evolutionary Biology. Philosophy of Science 47: 532-61.

Brandon, R. N. 1981. A Structural Description of Evolutionary Theory. In Asquith, P. D. \& Nickles, T. (eds.) PSA 1980, vol. 2. East Lansing, Michigan: Philosophy of Science Association, p. 427-39.

Cadevall i Soler, M. 1988. La estructura de la teoría de la evolución. Bellaterra: Universitat Autònoma de Barcelona.

Castle, W.E. 1903. The laws of Galton and Mendel and some laws governing race improvement by selection. Proceedings of the American Academy of Arts and Sciences 35: 233-42.

Crow, J.F. 1999. Hardy, Weinberg and Language Impediments. Genetics 152: 821-5.

Díez, J. A. \& Ibarra, A. 1988. Reseña de W. Balzer, C. U. Moulines, J. D. Sneed, An Architectonic for Science. The Structuralist Programm, Dordrecht, Reidel, 1987, 431+xxxvii págs. Theoria 7-8-9: 567-85.

Fodor, J. 1974. Special Sciences (or: the Disunity of Science as a Working Hypothesis). Synthese 28: 97-116.

—. 1991. Hedged Laws and Psychological Explanations. Mind 100: 19-33.

Gähde, U. 1982. T-Theoretizität und Holismus. In Leinfeliner, W., Kraemer, E. \& Schank, J. (eds.) Proceedings of the Sixth International Wittgenstein Symposium. Wien: HölderPichler-Tempsky, p. 327-30.

- 1983. T-Theoretizitat und Holismus. Frankfurt/Main-Bern: Peter Lang.

—. 1984. A Formal Approach to the Theory-Dependent Measurement. Philosophia Naturalis 21: 266-72.

Principia, 12(2) (2008), pp. 121-54. 
—. 1990. On Innertheoretical Conditions for Theoretical Terms. Erkenntnis 32: 21533.

Hardy, G. H. 1908. Mendelian Proportions in a Mixed Population. Science 28: 49-50.

Hartl, D.L. 1988. A Primer of Population Genetics. Sunderland, Mass.: Sinauer Associates, $2^{\text {nd }}$ ed.

Hull, D. 1974, Philosophy of Biological Science. Englewood Cliffs, New Jersey: PrenticeHall.

Jacquard, A. 1974. The Genetic Structure of Populattions. Berlin-Heidelberg-New York: Springer Verlag. Traducción de Structures Génétiques des Populations. Paris: Masson \& Cie, Editeurs, 1970.

Kitcher, P. 1993. The Advancement of Science. Science without Legend, Objectivity without Illusions. Oxford: Oxford University Press.

Lewontin, R. C. 1974. The Genetic Basis of Evolutionary Change. New York: Columbia University Press.

Lloyd, E. 1988. The Structure and Confirmation of Evolutionary Theory. New York: Greenwood Press.

Lorenzano, P. 2000. Classical Genetics and the Theory-Net of Genetics. In Balzer, W., Moulines, C. U. \& Sneed, J. (eds.) Structuralist Knowledge Representation: Paradigmatic Examples. Amsterdam: Rodopi, p. 251-84.

—. 2006. Fundamental Laws and Laws of Biology. In Ernst, G. \& Niebergall, K.-G. (eds) Philosophie der Wissenschaft - Wissenschaft der Philosophie. Festschrift für C. Ulises Moulines zum 60. Geburstag. Paderborn: Mentis-Verlag, p. 129-55.

- 2007. The Influence of Genetics on Philosophy of Science: Classical Genetics and the Structuralist View of Theories. In Fagot-Largeault, A., Torres, J. M. \& Rahman, S. (eds.) The Influence of Genetics on Contemporary Thinking. Dordrecht: Springer, p. 99115 .

Magalhães, J. C. \& Krause, D. 2000. Suppes Predicate for Genetics and Natural Selection. Journal of Theoretical Biology 209: 141-53.

Mayr, E. 1991. Eine neue Philosophie der Biologie. Darmstadt: Wissenschaftliche Buchgesellschaft.

Mosterín, J. 1984. Conceptos y teorías en la ciencia. Madrid: Alianza.

Moulines, C. U. 1978/1982. Forma y función de los principios-guía en las teorías físicas. In Moulines, C. U. Exploraciones metacientíficas. Madrid: Alianza, p. 88-107 (primera publicación como Moulines, C. U. 1978. Cuantificadores existenciales y principiosguía en las teorías físicas. Crítica 10: 59-88.)

—. 1991. Pluralidad y recursión. Madrid: Alianza.

Moya, A. 1989. Sobre la estructura de la teoría de la evolución. Barcelona: Anthropos.

Pearson, K. 1903. Mathematical contributions to the theory of evolution. XI. On the influence of natural selection on the variability and correlation of organs. Philosophical Transactions of the Royal Society of London, Ser. A 200: 1-66.

Principia, 12(2) (2008), pp. 121-54. 
Rosenberg, A. 1985. The Structure of Biological Science. Cambridge: Cambridge University Press.

Ruse, M. 1973. The Philosophy of Biology. London: Hutchinson.

Schaffner, K. F. 1993. Discovery and Explanation in Biology and Medicine. Chicago: The University of Chicago Press.

Sintonen, M. 1991. How Evolutionary Theory Faces the Reality. Synthese 89: 163-83.

Sneed, J. D. 1971. The Logical Structure of Mathematical Physics. Dordrecht: Reidel, 2a ed. revisada 1979.

Sober, E. 1984. The Nature of Selection: Evolutionary Theory in Philosophical Focus. Cambridge, Mass.: MIT Press.

—. 1993. Philosophy of Biology. Boulder/SanFrancisco: Westview Press.

Stegmüller, W. 1973. Theorienstrukturen und Theoriendynamik. Heidelberg: Springer.

— 1979a. The Structuralist View: Survey, Recent Development and Answers to Some Criticisms. In Niiniluoto, I. \& Tuomela, R. (eds.) The Logic and Epistemology of Scientific Change (Acta Philosophica Fennica 30). Amsterdam: North-Holland, p. 113-29.

—. 1979b. The Structuralist View of Theories. Berlin: Springer.

—. 1983. Erklärung-Begründung-Kausalität. Berlin/Heidelberg/New York: Springer, 2a ed. ampliada y modificada.

—. 1986. Theorie und Erfahrung, Band II, Dritter Halbband. Berlin/Heidelberg/New York: Springer.

Stern, C. 1943. The Hardy-Weinberg law. Science 97: 137-8.

Swartz, N. 1995. The Neo-Humean Perspective: Laws as Regularities. In Weinert, F. (ed.) Laws of Nature. Essays on the Philosophical, Scientific and Historical Dimensions. Berlin: de Gruyter, p. 67-91.

Thompson, P. 1989. The Structure of Biological Theories. Albany, N. Y.: State University of New York Press.

van Fraassen, B. 1977. The Only Necessity is Verbal Necessity. Journal of Philosophy 74: 71-85.

—. 1980. The Scientific Image. Oxford: Clarendon Press.

—. 1987. The Semantic Approach to Scientific Theories. In Nersessian, N. (ed.) The Process of Science. Dordrecht: Nijhoff, p. 105-24.

- 1993. Armstrong, Cartwright, and Earman on Laws and Symmetry. Philosophy and Phenomenological Research 53(2): 431-44.

Wassermann, G. D. 1981. On the Nature of the Theory of Evolution. Philosophy of Science 48: 416-37.

Weinberg, W. 1908. Über den Nachweis der Vererbung beim Menschen. Jahreshefte des Vereins für vaterländische Naturkunde in Württemberg 64: 368-82.

Williams, M. B. 1970. Deducing the Consequences of Evolution: A Mathematical Model. Journal of Theoretical Biology 29: 343-85.

Principia, 12(2) (2008), pp. 121-54. 


\section{Keywords}

Van Fraassen, Hardy-Weinberg law, classical population genetics, structuralist view of theories, fundamental law, specialization.

Pablo Lorenzano

Universidad Nacional de Quilmes/CONICET

pablol@unq.edu.ar

\section{Resumo}

O objetivo deste trabalho é discutir e desenvolver o diagnóstico que efetua van Fraassen (1987, p. 110) da lei de Hardy-Weinberg, de acordo coo qual esta: 1) não pode ser considerada uma lei a ser utilizada como un axioma da teoria genética de populações, pois é uma lei de equilíbrio que só vale sob certas condições especiais, 2) só determina uma subclasse de modelos, 3) sua generalização resulta vácua e 4) variantes complexas da lei podem ser deduzidas para pressupostos mais realistas. A discussão e desenvolvimento deste diagnóstico será levada a cabo tomando como base noções propostas por outra das concepções semânticas afim daquela desenvolvida por van Fraassen, a saber: a concepção estruturalista das teorias, e uma reconstrução da genética clássica de populações no marco de uma tal metateoria, também apresentada neste trabalho.

\section{Palavras-chave}

Van Fraassen, lei de Hardy-Weinberg, genética clássica de populações, concepção estruturalista das teorias, lei fundamental, especialização.

\section{Notas}

${ }^{1}$ La ecuación de arriba puede generalizarse para más de dos alelos y para casos de poliploidía (organismos que tienen más de dos copias de cada cromosoma). La generalización para más de dos alelos se obtendría del siguiente modo. Si consideramos el caso de una frecuencia alélica extra, $r$, en lugar de tener la expansión binomial de $(p+q)^{2}$, tenemos la expansión trinomial de $(p+q+r)^{2}$. Más generalmente, si consideramos los alelos $A_{1}, \ldots, A_{i}$ dados por las frecuencias alélicas $p_{1}$ a $p_{i}$, tendríamos $\left(p_{1}+\ldots+p_{i}\right)^{2}$, dando para todos los homocigotos: $f\left(A_{i} A_{i}\right)=p_{i}^{2}$ y para todos los heterocigotos: $f\left(A_{i} A_{j}\right)=2 p_{i} p_{j}$. La ecuación, generalizada a sistemas poliploides, sería la siguiente. Recordemos que el caso diploide es la expansión binomial de $(p+q)^{2}$; el caso poliploide es la expansión binomial de $(p+q)^{c}$, en donde $c$ es la ploidía. La fórmula completamente generalizada, que contempla tanto los alelos múltiples como la poliploidía, es la expansión multinomial de $\left(p_{1}+\ldots+p_{n}\right)^{c}$ :

$$
\left(p_{1}+\cdots+p_{n}\right)=\sum_{k_{1}, \ldots, k_{n}: k_{1}+\cdots+k_{n}=n}\left(n k_{1}, \ldots, k_{n}\right) p_{1}^{k_{1}} \cdots p_{n}^{k_{n}} .
$$

Principia, 12(2) (2008), pp. 121-54. 
2 Ver Weinert (1995) para una discusión en torno al concepto de ley de la naturaleza.

${ }^{3}$ Ver Stegmüller (1983) y Salmon (1989) para un análisis de las dificultades con las que se enfrenta la elucidación clásica del concepto de ley científica.

${ }^{4}$ Las expresiones "ley fundamental" y "ley especial" no se utilizan aquí en el sentido de Fodor $(1974,1991)$, como refiriéndose a leyes pertenecientes a distintos tipos de ciencias, fundamental o básica las primeras y especiales la segunda, sino en el sentido de la concepción estructuralista, es decir, como denotando distintos tipos de leyes de una y la misma teoría.

${ }^{5}$ Está claro que la consideración que se haga de este criterio, en cualquiera de sus versiones, tiene que tomar en cuenta que éste es fuertemente dependiente del respectivo lenguaje utilizado, e.e. de la respectiva formulación de una teoría, pues sólo en relación con ella es que un término puede ser considerado primitivo, básico o fundamental.

${ }^{6}$ Para acentuar que, a diferencia de lo que sucede de acuerdo con el análisis clásico, la relación entre las leyes más generales — las fundamentales_ y las más específicas no es de deducción, sino justamente de especialización (relación no-deductiva, reflexiva, antisimétrica y transitiva), es que las últimas son denominadas "leyes especiales" en lugar de "leyes derivadas".

${ }^{7}$ En caso de que las especificaciones introducidas resulten ser las apropiadas, se dice que las aplicaciones pretendidas devienen "exitosas". Mientras que en general es a través de las llamadas "aserciones (o afirmaciones) empíricas" asociadas a los distintos elementos teóricos que conforman una red teórica que se puede establecer una conexión entre este enfoque "semántico" o "modelo-teórico" y el enfoque clásico ("enunciativo"o "sintáctico"), son las "aserciones empíricas" asociadas a las leyes especiales que se encuentran en ese nivel las que en todo caso podrían ser sometidas al análisis tradicional de la contrastación, y de la consiguiente evaluación, de hipótesis.

${ }^{8}$ En ese trabajo (Moulines 1982), éste intenta dar cuenta del carácter cuasi-vacuo de las leyes fundamentales y de su condición de empíricamente irrestrictas, a través del análisis de su forma lógica, pudiendo ser visto como complemento del análisis del carácter sinóptico de las leyes. Basándose en los ejemplos del Segundo Principio de Newton - ley fundamental de mecánica (newtoniana) clásica de partículas- y de la ley fundamental de la termodinámica de los sistemas simples, Moulines señala dos características que ellas comparten: (1) que haya involucrados cuantificadores existenciales y (2) que al menos uno de los términos T-teóricos que allí ocurren sea una función de funciones o "funcional" y no simplemente una función, lo cual obliga a que la cuantificación existencial sea de segundo orden. Las leyes fundamentales que poseen estas dos características son denominadas por Moulines "principios-guía". Sin embargo, no toda ley fundamental es "principio-guía" en ese sentido. Hay leyes fundamentales con diferente forma lógica, así como también con términos teóricos que son funciones y no funcionales, tal como la ley de la conservación del momento, ley fundamental de la mecánica clásica del choque, al menos hasta el año 1685, en que la teoría es "incorporada" en su totalidad a

Principia, 12(2) (2008), pp. 121-54. 
la mecánica newtoniana. Por otro lado, este análisis de los principios-guía en función de su forma lógica tiene que enfrentarse al problema de la existencia de equivalentes lógicos, e.e. de enunciados lógicamente equivalentes con las formulaciones escogidas de los principios-guía pero con forma lógica distinta, además de, obviamente, ser relativo a la lógica utilizada en general.

9 Balzer \& Dowe (1990), Beatty (1980), Brandon (1981), Cadevall i Soler (1988), Hull (1974), Kitcher (1993), Lewontin (1974), Lloyd (1988), Magalhães \& Krause (2000), Mayr (1991), Moya (1989), Rosenberg (1985), Ruse (1973), Schaffner (1993), Sintonen (1991), Sober (1984, 1993), Thompson (1989), Wassermann (1981) y Williams (1970) son algunos de los autores que han trabajado en la clarificación de la estructura de la genética de poblaciones y de la teoría de la evolución por selección natural y de cuyo estudio nos hemos beneficiado en la elaboración del análisis aquí presentado. Por razones de espacio, no podemos incluir aquí una comparación entre tales análisis y el nuestro.

${ }^{10}$ En las estructuras consideradas no formulamos explícitamente los conjuntos básicos auxiliares (aquellos que tienen una interpretación puramente matemática, tal como el conjunto $\mathbb{R}$ de números reales) y nos restringimos a los conjuntos básicos principales (aquellos que obtienen una interpretación empírica).

${ }^{11}$ Para un fenotipo $\pi \in P$ y un conjunto de poblaciones $X \subseteq P o t(I)$, la frecuencia relativa de $\pi$ en $X, F R(\pi / X)$ se define del siguiente modo:

$F R(\pi / X)=($ el número de elementos en los conjuntos $i \in X$, para los que $\operatorname{APP}(i)=\pi$ ) entre (el número de elementos de elementos de $X$ ).

12 Aquí no se retoma el concepto probabilístico de distribución: no son utilizadas las características generales de las $\sigma$-álgebras. La reformulación es, no obstante, un asunto fundamentalmente terminológico (ver Balzer \& Dawe 1990). Si X es un conjunto finito, no vacío, entonces se entiende por una $\Gamma$-distribución sobre $X$ una función $p: X \rightarrow[0,1]$, tal que $\Sigma_{x \in X} \mathbf{p}(x)=1$. $[0,1]$ se refiere aquí al intervalo cerrado de los números reales entre 0 y 1 . Si se ordenan los elementos de $X$ de tal modo que una lista $\left\langle x_{1}, \ldots, x_{n}\right\rangle$ abarque exactamente todos los elementos $X$ 's, podrían escribirse los valores de la función de una $\gamma$-distribución $\mathbf{p}$ sobre $X$ con el mismo orden $\left\langle\mathbf{p}\left(x_{1}\right), \ldots, \mathbf{p}\left(x_{n}\right)\right\rangle=\left\langle\alpha_{1}, \ldots, \alpha_{n}\right\rangle$. Las $x^{\prime}$ 's son o bien fenotipos o bien genotipos. Para $x_{i}=\gamma_{i}$, por ejemplo, escribimos $\alpha_{i} \gamma_{i}$, a fines de determinar que $\alpha_{i}$ pertenece a $\gamma_{i}$. En la notación "abstracta" aquí utilizada, los $\gamma_{i}$ son "tragados" por medio de la distribución y recién reaparecen como sus argumentos: $\mathbf{p}\left(\gamma_{i}\right)=\alpha_{i}$, de forma tal que no es necesario escribirlos de manera expresa.

${ }^{13} \mathrm{Si}$ se considera conveniente tomar en cuenta el ambiente, por suponer que la determinación que llevan a cabo los genotipos de los fenotipos también depende de él, esto podría llevarse a cabo mediante las siguientes modificaciones: 1) introduciendo el conjunto finito, no-vacío, ENV de "ambientes" (variable $\epsilon:\left\{\epsilon_{1}, \ldots, \epsilon_{r}\right\}$ ), y 2) redefiniendo la función DET de la siguiente manera: DET: $G \times E N V \rightarrow P$ es suprayectiva (con $\operatorname{DET}(\gamma, \epsilon)=\pi$, para individuos, o bien $\operatorname{DET}\left(\left\langle\gamma_{1}, \ldots, \gamma_{s}\right\rangle, \epsilon\right)=\left\langle\pi_{1}, \ldots, \pi_{k}\right\rangle$, para poblaciones).

Principia, 12(2) (2008), pp. 121-54. 